University of Rhode Island

DigitalCommons@URI

Open Access Master's Theses

2016

\title{
A Multi-Component Evaporation Model to Determine the Onset of Crude Oil Emulsification in Seawater
}

Jennifer Anne Cragan

University of Rhode Island, jenna.cragan@gmail.com

Follow this and additional works at: https://digitalcommons.uri.edu/theses

\section{Recommended Citation}

Cragan, Jennifer Anne, "A Multi-Component Evaporation Model to Determine the Onset of Crude Oil Emulsification in Seawater" (2016). Open Access Master's Theses. Paper 957.

https://digitalcommons.uri.edu/theses/957

This Thesis is brought to you for free and open access by DigitalCommons@URI. It has been accepted for inclusion in Open Access Master's Theses by an authorized administrator of DigitalCommons@URI. For more information, please contact digitalcommons-group@uri.edu. 


\section{A MULTI-COMPONENT EVAPORATION MODEL TO \\ DETERMINE THE ONSET OF CRUDE OIL \\ EMULSIFICATION IN SEAWATER}

BY

JENNIFER ANNE CRAGAN

A THESIS SUBMITTED IN PARTIAL FULFILLMENT OF THE

REQUIREMENTS FOR THE DEGREE OF

MASTER OF SCIENCE

IN

OCEANOGRAPHY

UNIVERSITY OF RHODE ISLAND

2016 


\section{MASTER OF SCIENCE THESIS}

OF

JENNIFER ANNE CRAGAN

\section{APPROVED:}

Thesis Committee:

Major Professor Rainer Lohmann

Michael Greenfield

Brice Loose

Arthur Spivack

Nasser H. Zawia

DEAN OF THE GRADUATE SCHOOL

UNIVERSITY OF RHODE ISLAND

2016 


\begin{abstract}
Once crude oil is spilled in an aquatic environment, its emulsification state becomes a key property in combating the spill. The onset of emulsification has been hypothesized to be due to decreases in the solvent strength of bulk crude oil. To better predict when emulsification will occur, a compound-specific evaporation model was developed for crude oil spilled on surface seawater. A simple crude oil composition was constructed from 300 of the most commonly found crude oil constituents. Time varying evaporation rates of these constituents were derived by implementing a filmbased exchange model that utilized evolving bulk crude oil properties and chemical composition. A preliminary comparison between the proposed approach and common practice in oil spill modeling suggests that the component specific approach characterizes the evolution of bulk crude oil properties and composition reasonably well. Model predicted times to achieve empirically observed weathering percentages within the first 24 hours varied between 15 minutes and 5 hours of empirical observations for a subset of crude oils and fuels, with the model under-predicting the evaporation rate for light fuels and over-predicted weathering for heavier fuels. Comparisons of model constructed and empirical density data $(\mathrm{N}=17$, density range 859 - $936 \mathrm{~kg} \mathrm{~m}-3$ ) showed that the simple crude oil construct agreed within $3 \%$ of empirical values for the initial oil composition with laboratory weathered oil density values agreeing within $6 \%$. Bulk crude oil viscosity values calculated based on a friction-theory model showed poor agreement with empirical data at low and high viscosity values: over-predicting the empirical viscosity by up to $600 \%$ for empirical viscosity values below $50 \mathrm{mPa} . \mathrm{s}$, and under-predicting empirical viscosity results
\end{abstract}


greater than $300 \mathrm{mPa} . \mathrm{s}$ by $50 \%$. Model predicted viscosity values best agreed with empirical data in the $100-300 \mathrm{mPa}$.s range. Implementation of model predicted bulk data in an emulsion state calculation, however, showed that the model accurately predicted the emulsification state for 14 of 17 sampled crude oils. The time and weathering state for the onset of emulsification, a critical parameter for response operations, was accurately predicted for each of the 4 oils chosen for model comparison. The observed results suggest that the proposed model, even with the observed discrepancies in viscosity, is useful for predicting the onset and ultimate emulsification state of spilled crude oil. 


\section{ACKNOWLEDGMENTS}

The best result most often comes from the efforts of many. I would like to believe that this work represents something useful and good, and there are many people who have contributed to my ability to investigate and present both this thesis and the information contained therein. Foremost amongst them is my advisor, Rainer Lohmann. Rainer has been an avid and constant supporter of a most unconventional graduate student path, a considerate, thought-provoking, and thorough scientist, and a wonderful person to know. He has been a key component and proponent of this work, the result of the marriage of a work-related project with an academic pursuit. Rainer, and the members who graciously agreed to be on my committee, have been available when called upon, responsive, and provided several key components to the differentiation of this work. I thank Art Spivack for suggesting a means for implementing an energy limitation to evaporation, Michael Greenfield for pointing me towards a viscosity approach that aligned well with the general modeling approach, and Brice Loose for suggesting the use of a film transfer construct within the model to simplify things.

I would also like to acknowledge my colleagues at Maritime Planning Associates who have seen this effort through from notion to system: Matt Ward, for supporting and encouraging my academic pursuits; Christopher Mueller for his exceptional effort and skill in architecting the system and providing the analysis and visualization capabilities; and Peter Egli for his constant review and insightful questioning. Matt, Chris, and Pete have been inspiring colleagues and friends. The oil spill modeling work is but one facet of a larger modeling system, the building and improving of 
which has been championed intellectually and logistically by Rick Fry and Dr. Ron Meris at DTRA Reachback. Their support and encouragement has been an important motivator to this work.

Outside of work and academic realms, my family has been a source of enduring and unwavering support. I would like to thank my parents for instilling in me a belief that I could do most anything, often telling me that I shouldn't, and supporting me in all manners possible to keep going forward during the most challenging times. I would like to thank my sister Lynn for being a constant role model, friend, and cheerleader, teaching me that hard work was, indeed, its own reward. I would also like to thank my brother John for incessantly pushing me to do things that didn't seem feasible and showing me that being a daredevil was a useful life skill. Finally, I would like to thank my partner Ed and my daughter Violet for understanding many late nights of work, suggesting frozen meals and left-overs, and being the key to realizing that having a career and a family while being a student was doable. None of this would have been possible without their love and support. I am fortunate and truly grateful to have these people in my life. 


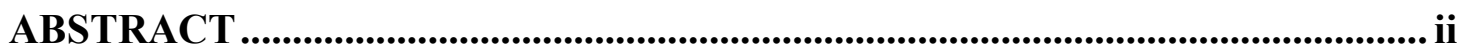

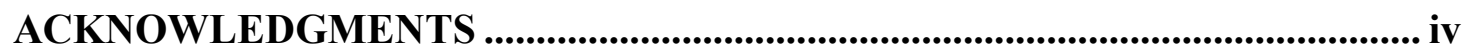

TABLE OF CONTENTS................................................................................. vi

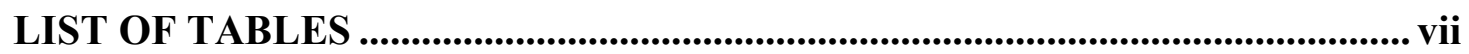

LIST OF FIGURES .................................................................................................... vii

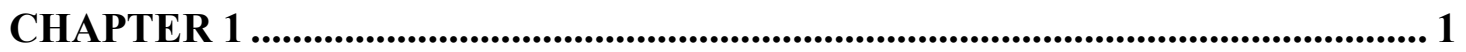

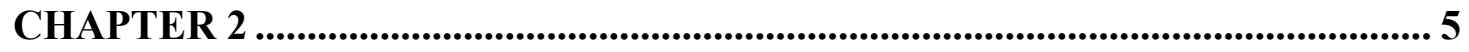

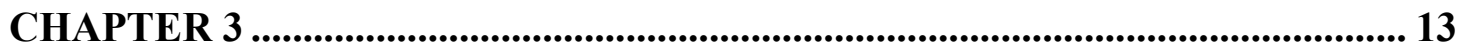

CHAPTER 4 ..................................................................................................................... 51

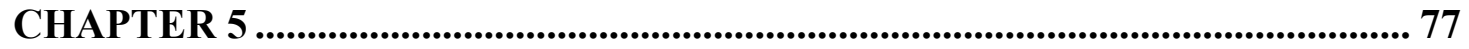

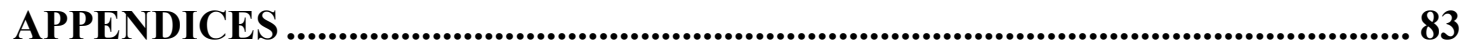

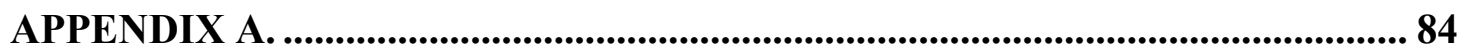

BIBLIOGRAPHY ............................................................................................................... 90 


\section{LIST OF TABLES}

TABLE

PAGE

Table 1: Typical approximate characteristics and properties of several crude oils ..... 19

Table 2: Example of pseudo-component categories and key physical properties for compounds within each pseudo-component class

Table 3: Basic properties of asphaltene and resin constituents............................... 23

Table 4: Residual friction coefficient parameters for calculating the reduced friction coefficients.

Table 5: Examples of overall transfer velocity coefficients.................................... 39

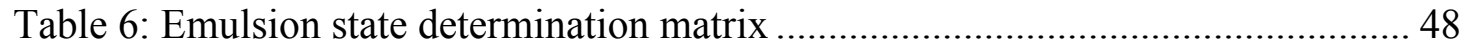

Table 7: Oil and water percentages for the various emulsion states ........................ 49

Table 8: Comparison of model predicted density for each of the saturate density values using the resultant linear least square slope and intercept. ..................................... 58

Table 9: Comparison of model calculated density to a subset of empirical density .... 59

Table 10: Oil characterization and comparison of model calculated mass-weighted viscosity, viscosity calculated using the linear friction theory approach, and empirical

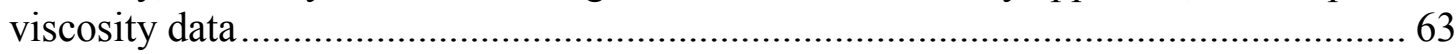

Table 11: Comparison of model calculated emulsification state prediction to empirical emulsion state observations.

Table 12. Comparison of observed and model predicted density, viscosity, and emulsification state for Arabian Light crude oil.

Table 13. Comparison of observed and model predicted density, viscosity, and emulsification state for Hondo crude oil.

Table 14. Comparison of observed and model predicted density, viscosity, and emulsification state for Santa Clara crude oil

Table 15. Comparison of observed and model predicted density, viscosity, and emulsification state for Anchorage Jet-Fuel. 


\section{LIST OF FIGURES}

FIGURE

PAGE

Figure 1. Ternary diagram representing the crude oil classifications and associated reserved characteristics 15

Figure 2. Additional classification of oil types within a similarly constructed ternary diagram. 16

Figure 3. Crude oil composition as a function of distillation temperature 18

Figure 4: Monthly mean surface upward longwave radiation flux $\left(\mathrm{W} \mathrm{m}^{-2}\right)$ for January (top) and July (bottom). 42

Figure 5: Viscosity and composition ranges for the 4 main emulsion types 50

Figure 6: Comparison of actual oil density and model predicted density $(\mathrm{g} / \mathrm{mL})$ for unweathered oils. Saturate density $0.727 \mathrm{~g} \mathrm{~mL}^{-1}$. 55

Figure 7: Comparison of actual oil density and model predicted density $(\mathrm{g} / \mathrm{mL})$ for unweathered oils. Saturate density $0.749 \mathrm{~g} \mathrm{~mL}^{-1}$ 56

Figure 8: Comparison of Actual Oil Density and Model Predicted Density $(\mathrm{g} / \mathrm{mL})$ for un-weathered oils. Saturate density $0.780 \mathrm{~g} \mathrm{~mL}^{-1}$ 57

Figure 9: Comparison of actual viscosity values (Fingas) and model predicted viscosity values (mPa.s) for the three methods of bulk viscosity calculations 64

Figure 10: Comparison of laboratory predicted evaporation curve and model predicted evaporation during the first 48 hours for Arabian Light crude oil. 73

Figure 11: Comparison of laboratory predicted evaporation curve and model predicted evaporation during the first 48 hours for Hondo crude oil 74

Figure 12: Comparison of laboratory predicted evaporation curve and model predicted evaporation during the first 48 hours for Santa Clara crude oil 75

Figure 13: Comparison of laboratory predicted evaporation curve and model predicted evaporation during the first 48 hours for Jet Fuel. 76 


\section{CHAPTER 1}

\section{INTRODUCTION}

Crude oil spills in aquatic environments cause significant damage to natural resources and can disrupt ecosystem health for decades (Chang et al. 2014). Crude oil consists of a complex mixture of thousands to potentially millions of organic chemicals, many of which are toxic to aquatic organisms and may bio-accumulate (Almeda et al. 2013, M. Greenfield, personal communication, April 22, 2016). Crude oil also contains a number of known carcinogens, posing a long-term hazard to human health. Economic impacts to fisheries and tourism as well as ecological impacts to marine organisms as a result of oil spills and their and transport can be extensive, potentially spanning decades (Moreno et al. 2013).

The 1967 Torrey Canyon oil spill was one of the first large scale oil spills, spurring the rapid development of mathematical modeling capabilities to predict the trajectory of spilled oil. Fay (1971) developed some of the first predictive equations for the spread of oil in the marine environment, ushering in a wave of oil spill models and research on crude oil behavior in the environment. With an estimated economic impact of $\$ 8.7$ billion dollars over 7 years (Sumalia, et al, 2012) to the Gulf of Mexico, the 2010 Deepwater Horizon blowout in the Gulf of Mexico has rekindled and intensified interest in oil spill modeling. 
Reasons for simulating an oil spill vary widely. Operations personnel need to know how changes in spilled oil behavior impact the ability to implement response techniques in the first hours to days of a spill. Newly spilled oil that has not undergone significant weathering is easiest to ignite. The ability to apply dispersants and avoid massive shoreline oiling is time-critical and also depends upon oil weathering. Weathered oil may no longer be positively buoyant, resulting in a transport trajectory that is significantly different than that of surface oil. Accurate oil spill modeling tools that provide bulk property information that determines the window of opportunity for effective booming, burning and response operations are critical for these purposes.

Spilled oil undergoes a number of transformations that significantly alter transport pathways. Oil slicks form on the surface of water as the result of the spreading of the (typically) less dense and barely soluble oil on the seawater surface from the effects of gravity as well as inertial, viscous, and frictional forces. Spreading oil is subject to evaporation of the more volatile components and dissolution. The rates of these may be enhanced by the generation of by-products from photo-oxidation (Garrett et al. 1998). Evaporation is the largest loss process for newly spilled oil, with $>30 \%$ of spilled oil mass lost to the atmosphere in the first 24 hours (Payne, 1991), depending on the type of oil. Within the marine environment oil may also adsorb to suspended particulate material, become stranded on shorelines, be microbially degraded, or be ingested by marine organisms. These degradation and dispersion 
processes are collectively referred to as weathering. Depending on the properties of the oil, it is possible that a water-in-oil emulsion may form.

The fate and transport of oil in an aquatic environment is primarily determined by the interaction of the physical and chemical properties of the oil with environmental forces including winds, currents, and tides. In the short term - hours to days - the four fundamental processes that determine the spatial and temporal extent of a crude oil spill are evaporation, dispersion, emulsification, and slick spreading. Slick spreading rates determine the surface area of spilled oil as well as slick thickness, which in turn impacts the evaporation rate. Most oil spill model (OSM) spreading calculations have their origins in the algorithms of Fay $(1969,1971)$ and Hoult (1972), though these equations are considered inaccurate for higher viscosity oils and subsurface releases of oil (Reed, 1999), such as the Macondo Well site in the Gulf of Mexico in April 2010.

When crude oil spills in the marine environment, it often forms water in oil emulsions, referred to as mousse (Thingstad \& Pengerud 1983). Butter is a common example of this type of emulsion. Emulsions form when two otherwise immiscible liquids are mixed together such that droplets of one liquid are dispersed within a continuous phase of the other. The emulsification process effectively results in an increase in the water content of spill oil. These emulsions can be stable, meso-stable, or unstable. Increased water content within the oil slick alters the physical properties and the transport characteristics and increases the overall volume of oil-contaminated material. It is not uncommon for emulsified heavy crude oil volumes to increase by a factor of three or more (Fingas, 2009). Bulk density changes from the inclusion of water in the oil mixture, often resulting in a neutrally buoyant mousse that may float 
just below the surface. Once a stable emulsion has formed, the effectiveness of booms, skimmers, and other response tools are greatly impeded, and in-situ burning ceases to be a response option (Reed, 1999). Emulsified oil is highly resistant to weathering.

Crude oils with relatively high asphaltene and resin components frequently form stable emulsions that can persist for months to years due to slow weathering. Shorterterm meso-stable and unstable emulsions also form. Asphaltenes are operationally defined by their precipitation from crude oil in pentane, hexane, or heptane and solubility in benzene or toluene. Asphaltenes have an estimated average molecular weight of 800 grams per mole (Wu, et al, 1998), and are generally planar in structure with an aromatic nature. Resins, considered slightly less polar than asphaltenes, have an average molecular weight of 750 grams per mole (Wu, et al, 1998) and can solvate asphaltenes in oil solution. Precipitated asphaltenes stabilize water-in-oil emulsions (Wu, et al, 1998). Knowing when and if spilled oil will emulsify helps guide the operational response tempo and options, allowing response crews to direct and maximize effectiveness. 


\section{CHAPTER 2}

\section{REVIEW OF LITERATURE}

\section{Background on existing models}

Most OSMs employ one of three approaches to modeling evaporation: 1.) The application of fractionated cut data from distillation curves, referred to as the pseudocomponent approach, 2.) Evaporative exposure (Stiver and MacKay, 1984) or 3.) predetermined loss rates based on laboratory observations of the changes in oil properties (Fingas, 1997). Pseudo-components are groups of compounds delineated by similar boiling point and solubility assumed to behave in a uniform manner (French-McCay and Payne, 2001). The evaporative exposure approach (Stiver and MacKay, 1984) was developed from empirical data; it assumes that evaporation is a function of oil composition and temperature only, using a bulk mass transfer coefficient that is a function of wind speed.

Fingas (2013) refuted the assumption of air-boundary layer limited evaporation rates, with a comparison to empirical data. Unlike water evaporation, which is airboundary limited, the atmospheric background concentration of the constituents of oil is effectively zero, and is minimally affected by temperature. This means that oil evaporation from the oil is diffusion limited by the oil itself, with oil temperature as the main factor determining the evaporation rate (Fingas, 2013). The variation of existing model short-term (hours) evaporative predictions is not significant, but can be 
$100 \%$ after several days as a result of the wind-speed dependence generating unrealistic evaporation rates.

The limiting air boundary-layer assumption has been the basis for the development of evaporation algorithms contained in most modern OSMs, thus evaporation rate algorithms that have been formulated as a function of wind speed require rethinking. Fingas (2013) stated that temperature and time are the only factors of significance in combination with static physical properties, while acknowledging that slick thickness does play a role in oil evaporation as a diffusion-limited process. The importance of both air and oil diffusion limitation is explored in Methods (Chapter 3), though both air and water limitation contributions were implemented within the model.

\section{Theory}

Evaporation is a simultaneous heat and mass transfer process, with the change from liquid to vapor phase taking sensible heat out of the bulk mixture in the form of latent heat with material exchange. Sensible heat transfer results in a change of temperature, while latent heat transfer is associated with a change of state without a change in temperature. In order to develop a method for verifying the heat and mass transfer rates that are consistent with the environmental conditions, heat and mass budgets must be developed. A mass budget, based on knowledge of the amount of each of the constituents present in crude oil, is straightforward to derive and track, because evaporation is the only mass loss term for our simplified model. There are 
numerous processes that are neglected in this simplification: biodegradation, photolysis, photo-oxidation, dissolution, and the turbulent generation of small droplets that may remain suspended in solution (referred to as dispersion). However in the short term (hours to several days), all of these processes with the exception of dispersion are significantly slower than evaporation, resulting in differences of less than $10 \%$ in the overall mass budget for spilled oil when excluded from the overall mass calculation (ITOPF 2016) .

\section{Heat Budget}

A heat budget for the evaporative process has several inherent uncertainties that must be simplified or eliminated to describe the energy available to support evaporation. The temperature for the spilled oil in the field must be determined. Because the background water volume is significantly greater than the oil spilled, the temperature of the water in direct contact with the spilled oil will be assumed to be the temperature of the spilled oil, with a negligible decrease in the temperature of the aquatic environment - i.e. evaporation will be assumed to be isothermal relative to the environment.. This relies on the assumption that the conductive heat transfer between the spilled oil and the ambient water occurs instantaneously.

For oil spilled in the coastal ocean, determining the available energy for heat and mass transfer requires several simplifying assumptions to provide a tractable solution to the problem of where the energy for evaporation comes from and how the energy requirement for continued evaporation is fulfilled. In a seawater-crude oil system 
characterized by laminar flow, the crude thermal conductivity would be slightly less than water, with crude oil in the range of $0.2 \mathrm{~W} \mathrm{~m}^{-1} \mathrm{~K}^{-1}$ (Jones 2012) and seawater in the range of $0.6 \mathrm{~W} \mathrm{~m}^{-1} \mathrm{~K}^{-1}$ at $25^{\circ} \mathrm{C}$ (Nayar et al. 2016; Sharqawy et al. 2011). This suggests that the crude oil temperature would change less quickly as a function of the overall loss of evaporating materials (and energy) compared to seawater. Further, the oil would be less sensitive to transient changes in seawater temperature. In reality, the flow regime would be better characterized as turbulent, and so the temperature of the spilled crude oil would be generally dictated by the surrounding seawater due the significantly larger overall volume of seawater present.

The validity of the assumption that the crude oil temperature is homogenous can be tested using a simple scaling argument. The Biot number for crude oil slicks is used a guideline for temperature uniformity. The Biot number is defined as the ratio of the internal and external heat transfer resistances. It is mathematically formulated as:

$$
\mathrm{Bi}=\frac{h L_{c}}{K}
$$

Where:

$\mathrm{h}=$ the heat transfer coefficient

$\mathrm{Lc}=$ the characteristic thickness

$\mathrm{K}=$ Thermal conductivity of the body

Non-emulsified oil surface slicks can range in thickness from less from 0.1 um up to $\mathrm{mm}$ ((NOAA 2012). The heat transfer coefficient range for crude oil is between 60 
and $300 \mathrm{~W} \mathrm{~m} \mathrm{~m}^{-2} \mathrm{~K}^{-1}$. The thermal conductivity of crude oil is reported to range from 0.1 to $0.2 \mathrm{~W} \mathrm{~m}^{-1} \mathrm{~K}^{-1}$. Using the minimum thickness, a heat transfer coefficient of $100 \mathrm{~W}$ $\mathrm{m}^{-2} \mathrm{~K}^{-1}$ and a thermal conductivity of $0.1 \mathrm{~W} \mathrm{~m}^{-1} \mathrm{~K}^{-1}$, the calculated Biot number is 0.001, indicating a thermally thin material with uniform temperature. For a $1 \mathrm{~mm}$ slick thickness, the calculated Biot number is 1 , suggesting the potential for a temperature gradient within the slick. Slick thicknesses of $1 \mathrm{~mm}$ are associated with crude oil emulsions, and would require modified heat transfer and thermal conductivity coefficients. For the case of emulsified crude oil emulsion, evaporation is assumed to be negligible within the model due to the significant uncertainty in the rate of the evaporation process for the oil-water mixture. Confining the problem to nonemulsified oils, crude oil slicks can be considered thermally thin and uniform in temperature.

The Biot number can be combined with the Fourier number, the ratio of the diffusive heat transport rate to the heat storage rate, to estimate the time to achieve a given temperature in the crude oil slick, assuming an initial oil temperature and a final seawater temperature. The Fourier number is typically formulated as:

$$
\mathrm{Fo}=\frac{\propto t}{L^{2}}
$$

Where:

$$
\begin{aligned}
& \propto=\text { the thermal diffusivity coefficient for crude oil }\left(\mathrm{m}^{2} \mathrm{~s}^{-1}\right) \\
& \mathrm{t}=\text { time scale of interest }(\mathrm{s}) \\
& \mathrm{L}=\text { length scale of interest }(\mathrm{m})
\end{aligned}
$$


Combining the Biot and Fourier numbers, and rearranging, we obtain the following equation:

$$
\mathrm{t}=\frac{\rho C_{p} V}{h A} \ln \left(\frac{T_{0}-T_{\infty}}{T-T_{\infty}}\right)
$$

Where:

$\rho=$ the density of the crude oil

$C_{p}=$ the specific heat capacity of the crude oil

$\mathrm{V}=$ the volume of crude oil

$\mathrm{H}=$ the thermal diffusivity coefficient of the surrounding water

$\mathrm{A}=$ the oil slick area

$T_{0}=$ the initial crude oil temperature

$\mathrm{T}=$ the temperature at time $\mathrm{t}$

$T_{\infty}=$ the bulk seawater temperature

Using an initial crude oil temperature of $350 \mathrm{~K}$, a slick thickness of $1 \times 10^{-6} \mathrm{~m}$, and a desired final temperature within $0.00001 \mathrm{~K}$ of an ambient temperature of $273 \mathrm{~K}$, it would take 0.55 seconds for thermal equilibrium for this system. The time increases to 55 seconds for a slick that is $0.1 \mathrm{~mm}$ thick. Alternatively, beginning with crude oil that is $250 \mathrm{~K}$, it would take 0.52 seconds for the crude oil slick to warm to the ambient temperature for a slick thickness of $1 \times 10^{-6} \mathrm{~m}$, and also approximately 55 seconds for a $0.1 \mathrm{~mm}$ oil slick to warm to ambient temperature. With a standard model timestep of 1 hour, the rapid speed of temperature equilibration justifies assuming an isothermal oil on water system. 


\section{Emulsification}

The emulsion state of an oil is a critical component to determining the overall fate and transport of oil spilled in an aquatic environment. Emulsification reduces the natural degradation and dispersion of the spilled oil while increasing both environmental persistence and the volume of oil-contaminated water. The onset of emulsification has been hypothesized to be due to decreases in solvent strength of bulk crude oil. Once oil becomes emulsified, it is assumed within the modeling framework that it is no longer subject to additional degradation processes, collectively referred to as weathering. Weathering, specifically dissolution and biodegradation, would continue to occur, however, the relative oil mass change as a function of time is small compared to the timeframe of interest (several days).

As mousse, discrete water droplets are dispersed within the oil continuum. The inclusion of water within the oil slick alters the physical properties and the transport characteristics, and increases the overall volume of material. It is not uncommon for emulsified heavy crude oil volumes to increase by a factor of three or more. The process of emulsification, combined with density changes due to the evaporation of the more volatile crude oil components, may result in the mousse becoming neutrally buoyant, floating just beneath the surface. An additional emulsion state for oil is entrained. The entrained state is typical of moderate viscosity oils.

The kinetics of crude oil emulsification are not well understood (Fingas, 2010), however it is generally considered to be fast once the criteria for emulsification are 
present. Fingas (2010) has proposed a set of criteria that contribute to the formation of the various stability categories of crude oil emulsions. The interaction of these criteria in the form of a stability function is used to determine if an oil is emulsified and what type of emulsion is formed. 


\section{CHAPTER 3}

\section{METHODOLOGY}

As the major loss term early in an oil spill, accurately determining the amount of oil evaporated is critical to providing the most accurate fate and transport predictions for oil spilled in aquatic environments. Although there are a number of modeling software packages available both commercially and publicly, these tools take a simple approach to an extremely dynamic problem. Despite a lack of complete knowledge of the vast number of constituents of crude oil, oil exploration and refining processes typically require data on components classes. Mass percentages of the four major component classes are most frequently available for oils and fuels: saturates, aromatics, resins, and asphaltenes as part of standard petroleum assays (SanchezMinero et al. 2013). These data, in conjunction with information about the major chemical constituents in these classes, can be used to track specific components critical to determining the evaporation rate of oil in aqueous environments. As evaporation proceeds, the less volatile saturated and aromatic components and their interactions with the resin and asphaltene content within the oil change. The evaporative loss of the solvent components changes both the solubility and the stability of the asphaltenic component, and may result in the development of a stable water-in-oil emulsion. With a more detailed approach to determining the evaporation rate, bulk oil properties and the impacts on the slick spreading rate and slick surface

area can be more tightly coupled. This tighter coupling is expected to provide a more accurate method for determining the fate and transport of spilled oil. 
To better address the short-term behavior of spilled crude oil and factors that contribute to emulsion formation, a multi-component oil spill model was developed that incorporates recent advances in the understanding of oil behavior. The primary goal was to develop a multi-component evaporation model to track the fate of a subset of commonly found components in crude oils, and evaluate its predictions against measured oil spill scenarios.

\section{Composition}

Crude oil contains thousands to potentially millions of individual chemical compounds, metals, and heteroatom (N, S) containing compounds (Liu \& Kujawinski 2015, M. Greenfield, personal communication, April 22, 2016). The relative amounts of each of these components vary between and within crude oil reservoirs. Once oil has been extracted from a well, components may be added or removed to promote stability during transport and ease of removal from storage tanks. Any molecular characterization of oil, therefore, is merely a snapshot of the oil, and must be assumed to be a best estimate. Typically, crude oil reservoirs are classified by the percentages of the overall constituents (Figure 1, Figure 2, Mobil Research and Engineering 1997)). Crude oil sub-types are further described within regions of the ternary diagram (Figure 2). Aromatics, within the following figures, include asphaltenic and resinous components. 
Figure 1. Ternary diagram representing the crude oil classifications and associated reserved characteristics (from https://courseware.e-

education.psu.edu/courses/egee101/L05_petroleum/L05_quality.html) accessed: $01 / 26 / 2016$

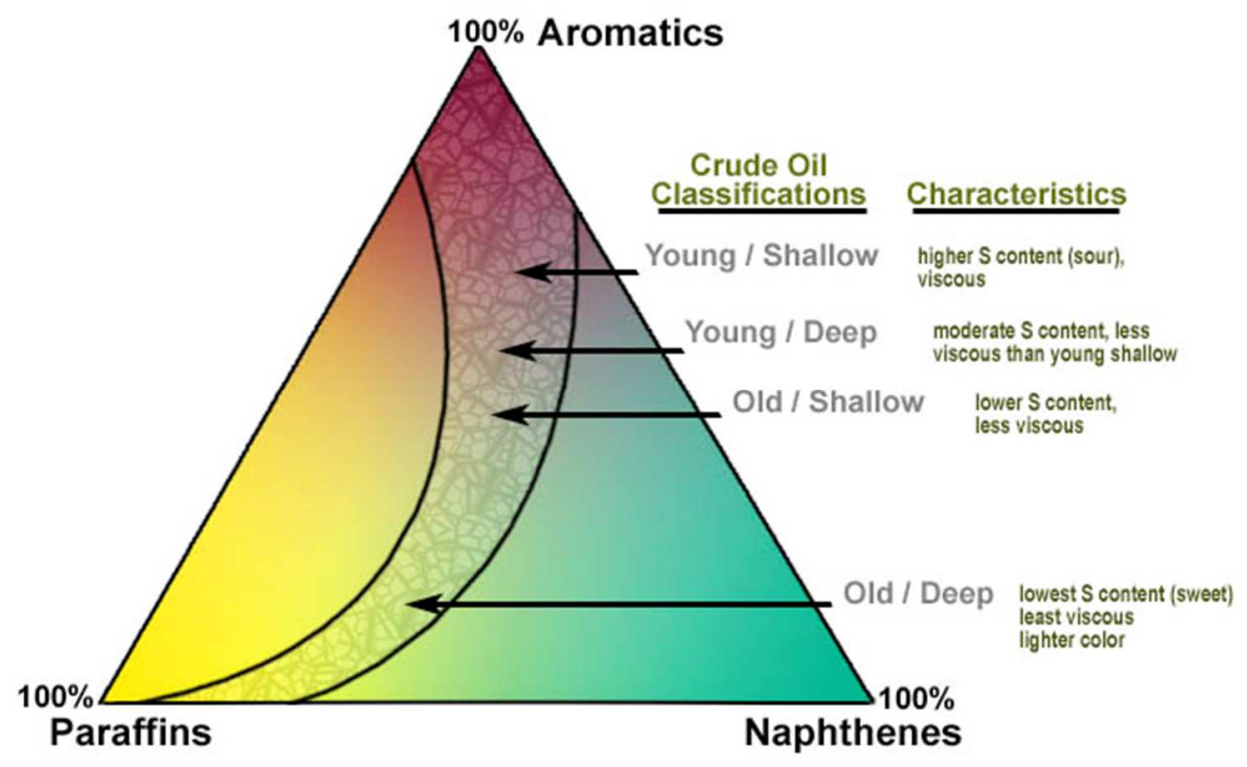


Figure 2. Additional classification of oil types within a similarly constructed ternary diagram (from Tissot and Welte, 1978).

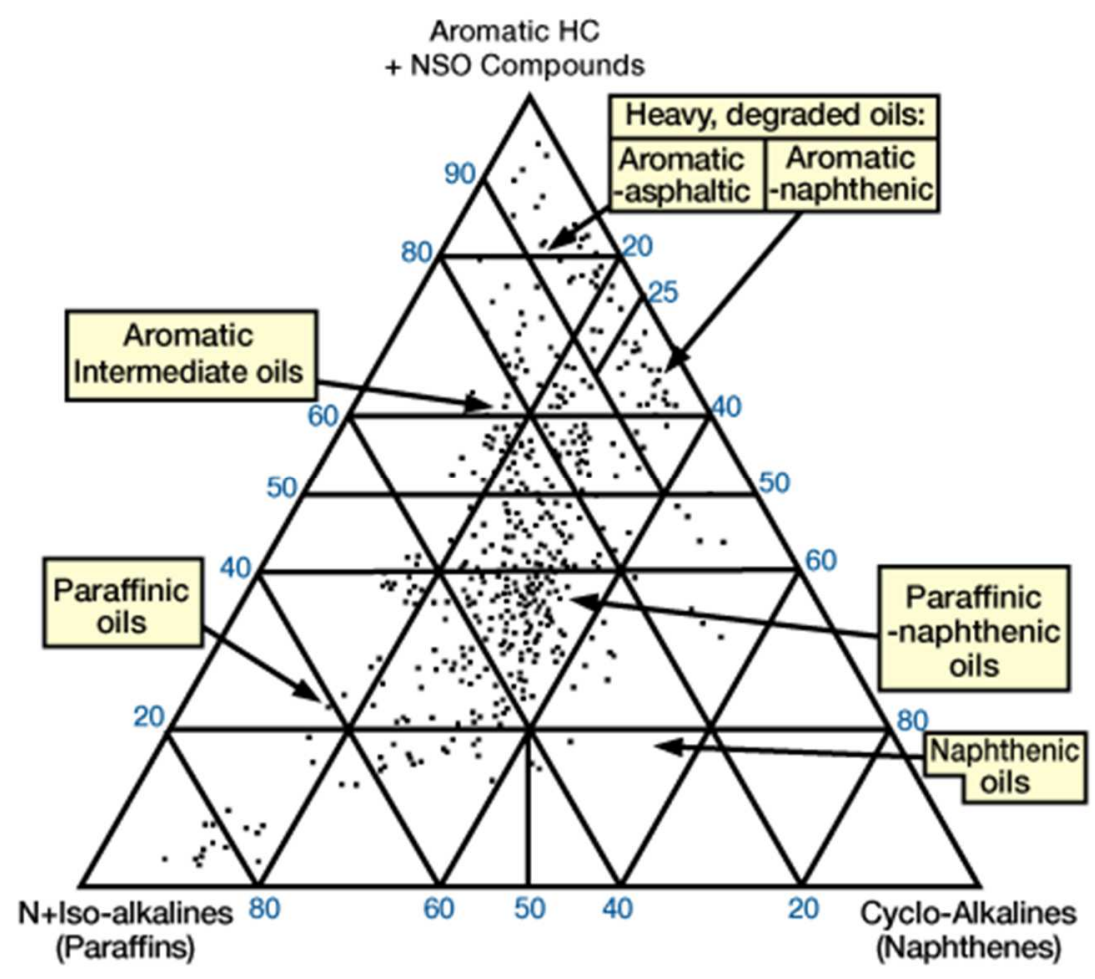


In the refining industry, crude oils are typically broken down by the fractions in which the chemicals are found post distillation. These fractions are represented as a function of distillation temperature (Figure 3), with lighter oils having higher paraffinic content.

The information contained in Figure $\mathbf{2}$ is broken down for a few different crude oil types by percentage in Table 1. Most existing oil spill models combine crude oil constituents within these broad categories by molecular weight or boiling point fraction for the purposes of evaporation. The resultant groupings are referred to as pseudo-components. Each pseudo-component can then have a unique evaporation rate, and pseudo-component loss rates are used to determine the vapor pressure of a spilled oil.

Table 2 presents a typical pseudo-component set and some of the key physical property ranges associated with the assigned pseudo-component. Of note is the fact that a very broad set of physical properties is represented within each of the component groups. This is a frequently used approach, and is generally reasonable given the variability in crude oil chemical composition, but likely over-generalizes the physical properties of individual compounds contained in crude oils. Further, this approach does not account for the impact of external environmental parameters such as water temperature on the evaporation rate of the material.

The work performed here leverages advances in both computer processing speeds and analytical methods for determining composition of different crude oils. It combines the crude oil type composition and percentages of components in concert 
Figure 3. Crude oil composition as a function of distillation temperature (from Mobil, 1997)

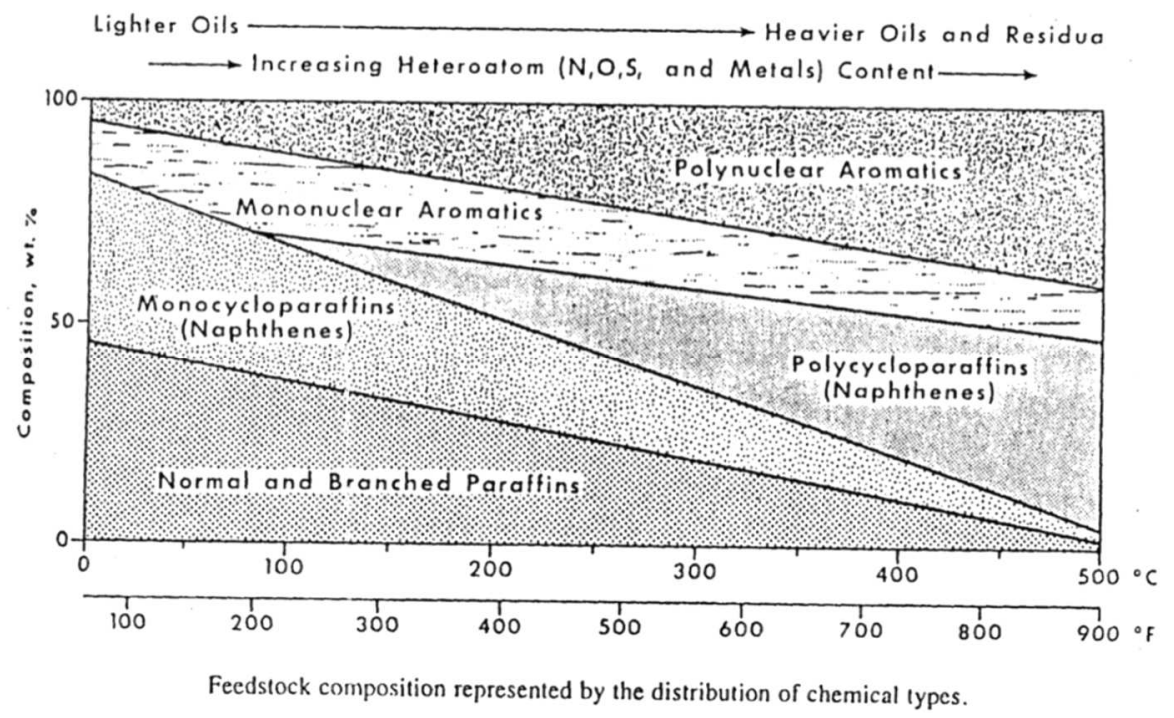


Table 1: Typical approximate characteristics and properties of several crude oils

\begin{tabular}{lccc}
\hline Crude source & Paraffins (\% vol) & Aromatics (\% vol) & Naphthenes (\% vol) \\
\hline Nigerian - Light & 37 & 9 & 54 \\
Saudi - Light & 63 & 19 & 18 \\
Saudi - Heavy & 60 & 15 & 25 \\
Venezuela - Heavy & 35 & 12 & 53 \\
Venezuela - Light & 52 & 14 & 34 \\
USA - W. Texas Sour & 46 & 22 & 32 \\
North Sea - Brent & 50 & 16 & 34
\end{tabular}


Table 2: Example of pseudo-component categories and key physical properties for compounds within each pseudo-component class. There are many components represented by a single pseudo-components assigned properties. After (Dietrich et al. 2014).

\begin{tabular}{ccccc}
\hline Description & $\begin{array}{c}\text { Carbon \# } \\
\text { Range }\end{array}$ & $\begin{array}{c}\text { Density } \\
(\mathbf{g} / \mathbf{m L})\end{array}$ & $\begin{array}{c}\text { Boiling } \\
\text { Point }\left({ }^{\circ} \mathbf{C}\right)\end{array}$ & $\begin{array}{c}\text { Molecular } \\
\text { Weight }(\mathbf{g} / \mathbf{m o l})\end{array}$ \\
\hline Paraffin & C06-C12 & $0.66-0.77$ & $69-230$ & $86-170$ \\
Paraffin & C13-C25 & $0.77-0.78$ & $230-405$ & $184-352$ \\
Cycloparaffin & C06-C12 & $0.75-0.9$ & $70-230$ & $84-164$ \\
Cycloparaffin & C13-C25 & $0.9-1$ & $230-405$ & $156-318$ \\
1 +2 Ring Aromatics & C06-C11 & $0.88-1.1$ & $80-240$ & $78-143$ \\
Polycyclic Aromatics & C12-C18 & $1.1-1.2$ & $240-400$ & $128-234$ \\
Naphtheno-Aromatic & C09-C25 & $0.97-1.2$ & $180-400$ & $116-300$ \\
$\begin{array}{c}\text { Residuals, including } \\
\text { heterocyclic compounds }\end{array}$ & Various & 1.1 & 400 & $300-900$
\end{tabular}


with individual chemicals and chemical properties in order to provide a dynamic, environmentally linked fate and transport model for spilled oil. Chemical composition is determined continuously throughout a modeling simulation. With this information, it is then possible to better define the evolution of bulk oil properties and capture the impact of changes to the bulk properties on the weathering of the oil.

A simplified methodology was adopted to assign and refine a generic crude oil composition. A list of compounds commonly found in crude oil was compiled based on investigation of several different published compositions (Ryerson et al. 2012; Reddy et al. 2012; Sørheim et al. 2011; Leirvik \& Myrhaug 2009), and used as the basis for developing a generic crude oil composition. The relative amounts of the identified compounds or pseudo-component classes in un-weathered oils from the Macondo Deepwater Horizon Spill (Reddy et al. 2012; Ryerson et al. 2012), Gjøa crude oil (Sørheim et al. 2011), and several crude oils that make up the Alvheim blend (Leirvik \& Myrhaug 2009) were compiled and averaged to develop the preliminary generic composite oil for saturate and aromatic component classes.

\section{Bulk Oil Properties}

The bulk properties of immediate interest to the fate and transport of spilled oil are density, viscosity, and surface tension. These properties control the fate and transport of spilled oil through their impact on slick spreading and the overall transfer of evaporating components. In the modeling framework, all three of these properties 
were initially determined at each timestep as the instantaneous mass or mole weighted sums of the partial contributions of the individual chemical property and the amount of that material present:

$$
\text { Property }_{B u l k}=\frac{\Sigma\left(M_{i} * P_{i}\right)}{\Sigma M_{i}}
$$

where:

$\mathrm{M}_{i}$ is the mass or moles of constituent $\mathrm{i}$, and $\mathrm{P}_{i}$ is the constituent property of interest for constituent $\mathrm{i}$

In order to generate the bulk properties for crude oil, physical properties were needed for both the asphaltene and resin components. Density, viscosity, and surface tension values for the generic asphaltene and resin constituents are compiled based on literature information on these complex component classes (Da Silva (2001), Wu and Prausnitz (1998)). There is significant uncertainty in these numbers, as asphaltenes extracted from crude oils are described as 'friable solids', and the liquid range viscosity value may have been derived, themselves, to fit a model for physical properties (M. Greenfield, personal communication, April 22, 2016). 
Table 3: Basic properties of asphaltene and resin constituents, derived from Da Silva (2001) and $\mathrm{Wu}$ and Prausnitz (1998) at $25^{\circ} \mathrm{C}$.

\begin{tabular}{lcc}
\hline Property & Asphaltene & Resin \\
\hline Density $\left(\mathrm{kg} \mathrm{m}^{-3}\right)$ & 1120 & 1080 \\
Viscosity $(\mathrm{mPa} . \mathrm{s})$ & 2.24 & 1.728 \\
Surface Tension $\left(\right.$ dyne $\left.\mathrm{cm}^{-1}\right)$ & 28 & 30 \\
Molecular Weight & 750 & 800
\end{tabular}


The accuracy of the calculated general bulk property depends on defining appropriate temperature dependent values for the individual constituents. Literature data are generally compiled for standard temperature and pressure conditions, and often this is not appropriate for environmental conditions. To this end, temperature dependent surface tension and viscosity empirical fit equations were applied to the chemical constituents where the data could be located. Individual chemical viscosity and surface tension algorithms were implemented to allow for temperature-specific values where data or fitting coefficients were available. The methods for calculating the temperature adjusted values for viscosity and surface tension values are detailed in the following sections.

\section{Density}

Although density is also temperature dependent, the availability of fitting coefficients for the crude oil constituents was limited. A temperature correction was thus not performed.

\section{Surface Tension}

The temperature dependent surface tension of the individual oil constituents was calculated using one of two methods where fitting coefficients were available: the full or the condensed version of the Design Institute for Physical Properties Research (DIPPR) 106 regression equation (DDBSP, 2014). The full equation is,

$$
\sigma(\text { dyne } / \mathrm{cm})=C_{0}\left(1-T_{r}\right)^{C_{1}+C_{2} T_{r}+C_{3} T_{r}^{2}+C_{4} T_{r}^{3}}
$$


where:

$T_{r}=\frac{\text { Ambient Temperature }(K)}{\text { Critical Temperature }(K)}$

and

$\mathrm{C}_{\mathrm{x}}$ is to an empirically derived fitting coefficient.

The abbreviated DIPPR equation is:

$$
\sigma(\text { dyne } / \mathrm{cm})=C_{0}\left(1-T_{r}\right)^{C_{1}}(6)
$$

with coefficients and variables having the same definitions as above.

Viscosity

Dynamic viscosity is a measure of the internal friction of a moving fluid that causes adjacent layers to move in parallel but at different speeds (shear flow). The parameterization of viscosity is fundamental to the dispersive characteristics of the constituent in the aqueous environment. Specifically, dynamic viscosity is used to determine the maximum surface area for a spilled oil, as well as the mass transfer of material via evaporation. Tabulated viscosity constants $\left(\mathrm{kg} \mathrm{m}^{-1} \mathrm{~s}^{-1}\right)$ for individual constituents were compiled for standard temperature and pressure. Several previously published equation formats were implemented to provide temperature dependency for the bulk property calculation for viscosity within the model. The identified equation formats are reviewed in the following paragraphs. 
Three methods for calculating viscosity were located and implemented to provide temperature dependent viscosity values for the individual oil constituents. The first is the extended Andrade equation (DDBSP, 2014):

$$
\eta(c P)=\exp ^{C_{0}+C_{1} / T+C_{2} T+C_{3} T^{2}}(7)
$$

where $\mathrm{T}$ is in Kelvin and $\mathrm{C}_{\mathrm{x}}$ represents a chemical specific fitting coefficient. The resulting constituent viscosity is converted to units of $\mathrm{kg} \mathrm{m}-1 \mathrm{~s}-1$ (Pa-s) in order to align with standard units within the model. There is also an empirically derived polynomial equation (Infotherm, 2009):

$$
\eta\left(k g m^{-1} s^{-1}\right)=C_{0}+C_{1} T+C_{2} T^{2}+C_{3} T^{3}(8)
$$

where $\mathrm{T}$ is in Kelvin and $\mathrm{C}_{\mathrm{x}}$ represents a chemical specific fitting coefficient. Finally, Yaws (2009) also presented fitting data to calculate the temperature-adjusted viscosity:

$$
\eta\left(k g m^{-1} s^{-1}\right)=F_{C} 10^{\left(C_{0}+\frac{C_{1}}{T}+C_{2} T+C_{3} T^{2}\right)}(9)
$$

where $\mathrm{T}$ is in degrees Kelvin, $\mathrm{C}_{\mathrm{x}}$ represents a chemical specific fitting coefficient, and $\mathrm{F}_{\mathrm{C}}$ is a unit conversion factor $=0.001$. 


\section{Bulk Density}

Bulk density was calculated as the mass-weighted average of the individual crude oil constituents. Bulk density is calculated at each timestep within the model, accounting for composition changes in the resultant density value. Although individual constituent data is largely reported at $25^{\circ} \mathrm{C}$, crude oil density is more often reported at $15^{\circ} \mathrm{C}$. In order to convert empirical results to a reference temperature to test the individual constituents, Manning and Thompson's equation to adjust crude oil density to a temperature other than $15^{\circ} \mathrm{C}$ was used:

$$
S G_{T}=S G_{15}-5.93 \times 10^{-4} *\left(T\left({ }^{\circ} \mathrm{C}\right)-15\right)
$$

where:

$S G_{T}=$ Specific gravity of a given crude oil at the desired temperature ${ }^{\circ} \mathrm{C}$ $S G_{15}=$ Specific gravity of a given crude oil at $15^{\circ} \mathrm{C}$ $T\left({ }^{\circ} \mathrm{C}\right)=$ Temperature in degrees Celsius

\section{Bulk Viscosity}

Estimation of bulk crude oil viscosity is a challenging task and has been the source of significant investigation (Quiñones-Cisneros et al. 2001a; Quiñones-Cisneros et al. 2001b; Quiñones-Cisneros et al. 2004; Baylaucq et al. 2006; Quiñones-Cisneros \& Deiters 2006; Quiñones-Cisneros et al. 2008; Quiñones-Cisneros et al. 2015). Methods that calculate viscosity as a function of density are potentially subject to additional errors if the density is not measured, as is the case for this work. Additionally, the viscosity of oils varies greatly as a function of gas content. Dead oil - oil with no gas content - viscosity correlations have very different dependencies 
than live oils - freshly released oil from a reservoir with significant gaseous components. Very heavy oil (density greater than $1000 \mathrm{~kg} \mathrm{~m}^{-3}$ ) viscosity correlations between calculated and measured values are also different from heavy, medium, and light crude oil viscosities. For the purposes of this work, it was assumed that the oils were all dead.

Several methods for calculating the bulk viscosity of crude oil were investigated for agreement with empirical data and use within the model. The first approach was the simple mass-weight contribution approach described above. The second method was to apply the Beal method (Beal, 1970) to calculate oil viscosity $(\mu)$ as a function of temperature $\left(\mathrm{T},{ }^{\circ} \mathrm{F}\right)$ and bulk density as follows:

$$
\mu=0.32+\left(\frac{1.8 \times 10^{7}}{A P I^{4.53}}\right)\left(\frac{360}{T+200}\right)^{a}
$$

where:

$\mathrm{a}=10^{\left(0.43+\left(\frac{833}{A P I}\right)\right)}$

$A P I=\frac{141.5}{\text { density }}-131.5$

with density in units of $\mathrm{g} / \mathrm{mL}$.

The final method was to use the linear friction theory method developed and proposed by Quiñones-Cisneros et al. (2000, 2001a, 2001b, 2004, 2006, 2008). Briefly, this approach posits that viscosity can be treated as the sum of two components: the dilute gas viscosity $\left(\eta_{\text {gas }}\right)$ of a constituent and the residual friction viscosity $\left(\eta_{f}\right)$ : 


$$
\eta=\eta_{g a s}+\eta_{f}
$$

The friction component, in turn can be expanded to include an attractive and repulsive term similar to pressure in cubic equations of state:

$$
\eta_{f}=\eta_{a}+\eta_{r}
$$

The attractive and repulsive friction contributions are related to the attractive and repulsive pressure contributions to a system by friction coefficients $(\mathrm{K})$ as follows:

$$
\eta_{f}=\kappa_{a} p_{a}+\kappa_{r} p_{r}+\kappa_{r r} p_{r}^{2}
$$

Further research by Quinones (Quiñones-Cisneros et al. 2003) resulted in a modification to the original approach, and suggested that by implementing a corresponding states approach, reduced friction $\left(\hat{\eta}_{f}\right)$ can be defined as:

$$
\hat{\eta}_{f}=\frac{\eta_{f}}{\eta_{c}}
$$


where $\eta_{c}$ is the critical viscosity, the viscosity at the critical point. The critical viscosity can be calculated from an empirical relationship to critical pressure and molecular weight:

$$
\eta_{c}=0.597556 * p_{c} * M W^{0.601652}
$$

The reduced viscosity can be rewritten as the sum of reduced repulsive $\left(\hat{\eta}_{r}\right)$ and attractive $\left(\hat{\eta}_{a}\right)$ contributions:

$$
\hat{\eta}_{f}=\hat{\eta}_{r}+\hat{\eta}_{a}
$$

Each of the terms can be further expanded as follows:

$$
\begin{gathered}
\hat{\eta}_{a}=\hat{\kappa}_{a}\left(\frac{p_{a}}{p_{c}}\right) \\
\hat{\eta}_{r}=\hat{\kappa}_{r}\left(\frac{p_{r}}{p_{c}}\right)+\hat{\kappa}_{r r}\left(\frac{p_{r}}{p_{c}}\right)^{2}
\end{gathered}
$$

with the reduced friction coefficients $\left(\hat{\kappa}_{a}, \hat{\kappa}_{r}\right.$ and $\left.\hat{\kappa}_{r r}\right)$ represented as the sum of a temperature independent critical friction component $\left(\hat{\kappa}_{x}^{c}\right)$ and a residual friction coefficient $\left(\Delta \hat{\kappa}_{x}\right)$ to arrive at the overall reduced friction coefficient:

$$
\begin{aligned}
& \hat{\kappa}_{a}=\hat{\kappa}_{a}^{c}+\Delta \hat{\kappa}_{a} \\
& \hat{\kappa}_{r}=\hat{\kappa}_{r}^{c}+\Delta \hat{\kappa}_{r} \\
& \hat{\kappa}_{r r}=\hat{\kappa}_{r r}^{c}+\Delta \hat{\kappa}_{r r}(22)
\end{aligned}
$$


The residual friction coefficients can be calculated as a function of critical temperature and critical pressure using the set of equations:

$$
\begin{gathered}
\Delta \hat{\kappa}_{a}=\kappa_{a, 0,0}(\Gamma-1)+\left(\kappa_{a, 1,0}+\kappa_{a, 1,1} \psi\right) *(\exp (\Gamma-1)-1)+\left(\kappa_{a, 2,0}+\kappa_{a, 2,1} \psi+\right. \\
\left.\kappa_{a, 2,2} \psi^{2}\right) *(\exp (2 \Gamma-2)-1) \\
\Delta \hat{\kappa}_{r}=\kappa_{r, 0,0}(\Gamma-1)+\left(\kappa_{r, 1,0}+\kappa_{r, 1,1} \psi\right) *(\exp (\Gamma-1)-1)+\left(\kappa_{r, 2,0}+\kappa_{r, 2,1} \psi+\right. \\
\left.\kappa_{r, 2,2} \psi^{2}\right) *(\exp (2 \Gamma-2)-1) \\
\Delta \hat{\kappa}_{r r}=\kappa_{r, 2,1} \psi *(\exp (2 \Gamma)-1)(\Gamma-1)^{2}
\end{gathered}
$$

where:

$\Gamma=\frac{T_{c}}{T}$, and

$\psi=\frac{R T_{c}}{p_{c}}$

Quinones-Cisñeros (2001a) examined the individual coefficients contained within these equation and proposed a universal set of constants that could be applied for determining the residual friction components and the critical reduced friction parameters, as a function of the equation of state used. The Peng-Robinson, StryjekVera Equation of State (PRSV-EOS) was used as the method for comparing bulk viscosity calculations. The PRSV-EOS is well suited to hydrocarbons and is widely used in the determination of the hydrocarbon mixture properties. Table 4 displays the residual and fitted individual friction coefficients that correspond to the PRSV-EOS. 
Table 4: Residual friction coefficient parameters for calculating the reduced friction coefficients. These coefficients are for the Peng-Robinson-Stryjek-Vera Equation of State

\begin{tabular}{crcr}
\hline Parameter & \multicolumn{1}{c}{ Value } & Parameter & \multicolumn{1}{c}{ Value } \\
\hline$\hat{\kappa}_{a}^{c}$ & -0.140464 & $\kappa_{a, 2,2}$ & $-5.91258 \times 10^{-9}$ \\
$\hat{\kappa}_{r}^{c}$ & 0.0119902 & $\kappa_{r, 0,0}$ & -0.325026 \\
$\hat{\kappa}_{r r}^{c}$ & 0.000855115 & $\kappa_{r, 1,0}$ & 0.586974 \\
$\kappa_{a, 0,0}$ & 0.0261033 & $\kappa_{r, 1,1}$ & $-3.70512 \times 10^{-5}$ \\
$\kappa_{a, 1,0}$ & 0.194487 & $\kappa_{r, 2,0}$ & -0.0764774 \\
$\kappa_{a, 1,1}$ & $-1.00432 \times 10^{-4}$ & $\kappa_{r, 2,1}$ & $3.38714 \times 10^{-5}$ \\
$\kappa_{a, 2,0}$ & -0.0401761 & $\kappa_{r, 2,2}$ & $-6.32233 \times 10^{-9}$ \\
$\kappa_{a, 2,1}$ & $3.94113 \times 10^{-5}$ & $\kappa_{r r, 2,1}$ & $1.43698 \times 10^{-8}$
\end{tabular}


Viscosity values for each component were calculated and summed to develop a mass based mixture value for the dilute gas and friction components:

$$
\eta_{m x}=\eta_{0, m x}+\eta_{f, m x}
$$

where:

$$
\begin{aligned}
& \eta_{0, m x}=\exp \left[\sum_{i=1}^{n} x_{i} \ln \left(\eta_{0,1}\right)\right] \\
& \eta_{f, m x}=\exp \left[\sum_{i=1}^{n} x_{i} \ln \left(\eta_{f, 1}\right)\right]
\end{aligned}
$$

The friction contribution mixing rules used for this work were a slight departure from that implemented by Quinones-Cisneros, as the weighted mixing method proposed could not be easily implemented in a dynamic manner within the proposed modeling construct. The results of all three viscosity methods are presented in Chapter 4 .

\section{Evaporation}

A simple evaporation model was implemented to determine the mass flux per model timestep on a component-by-component basis. Evaporation is the process of transfer from the liquid phase to the vapor phase, and is applied to non-dissolved materials above a certain depth in the water column for the purposes of the model. Within the model, the molar amount of each non-dissolved constituent within the mass weighted bulk material composite that evaporates at each timestep is calculated in the following manner: 


$$
M_{\text {evap }}=F_{\text {evap }} * A_{\text {surf }} * t
$$

where:

$\mathrm{t}$ is the model timestep

$A_{\text {surf }}$ is the surface area $\left(\mathrm{m}^{2}\right)$ of the slick (here parcel of the slick)

$\mathrm{F}_{\text {evap }}$ is the calculated evaporative flux $\left(\mathrm{mol} \mathrm{m}^{-2} \mathrm{~s}^{-1}\right)$

Evaporation is calculated as a function of the overall mass transfer coefficient and the amount of material in the surface oil. A film-based exchange model is used to determine the net evaporative flux (F) for air-sea exchange .(Deacon 1977) The overall flux equation is:

$$
F=k\left(C_{w}-C_{e q}\right)
$$

where:

$\mathrm{k}=$ the overall transfer coefficient $\mathrm{cm} \mathrm{s}^{-1}$

$\mathrm{C}_{\mathrm{w}}=$ the concentration of the material in the water (oil phase for the model)

$\mathrm{C}_{\mathrm{eq}}=$ the equilibrium atmospheric concentration.

Because the atmosphere is an open-ended boundary, the equilibrium concentration above the air-water interface can be effectively ignored, simplifying the equation to the following:

$$
F=k * C_{w}
$$


The overall transfer coefficient $(\mathrm{k})$ is calculated as function of the air-phase and water-phase diffusivities (Deacon 1977):

$$
\frac{1}{k_{\text {overall }}}=\frac{1}{v_{\text {air }}} \frac{H}{R T}+\frac{1}{v_{\text {water }}}
$$

where:

$\mathrm{V}_{\text {water }}=$ the exchange velocity in water $\left(\mathrm{cm} \mathrm{s}^{-1}\right)$ for a given constituent

$\mathrm{V}_{\text {air }}=$ the exchange velocity in $\operatorname{air}\left(\mathrm{cm} \mathrm{s}^{-1}\right)$

$\mathrm{H}=$ the Henry's Law Constant $\left(\mathrm{m}^{3}\right.$ atm $\left.\mathrm{mol}^{-1}\right)$

$\mathrm{R}=$ the ideal gas constant, here $8.21 \times 10^{-5} \mathrm{~m}^{3}$ atm $\mathrm{mol}^{-1} \mathrm{~K}^{-1}$

$\mathrm{T}=$ Temperature (Kelvin)

The flux determination is based on the combined air-phase and water-phase exchange velocities. The air-phase velocity is based on the methodology of MacKay and Yeun (1983), and is related to the exchange velocity of water:

$$
v_{\text {air }}=\left(\frac{D_{i a}}{D_{\mathrm{H}_{2} \mathrm{O}}}\right)^{0.67} v_{\text {water }, \text { air }}
$$

where:

$\mathrm{V}_{\text {air }}=$ the velocity of the substance in $\operatorname{air}\left(\mathrm{cm} \mathrm{s}^{-1}\right)$

$\mathrm{D}_{\mathrm{ia}}$ - the diffusivity of the compound of interest in air $\left(\mathrm{cm}^{2} \mathrm{~s}^{-1}\right)$

$\mathrm{D}_{\mathrm{H} 2 \mathrm{O}}=$ the diffusivity of water vapor in $\operatorname{air}\left(\mathrm{cm}^{2} \mathrm{~s}^{-1}\right)$

$\mathrm{v}_{\text {water,air }}=$ the velocity of water vapor in air $\left(\mathrm{cm} \mathrm{s}^{-1}\right)$ 
An approximation of the velocity of water vapor is based on the analysis of Schwarzenbach, et al. (2003), which indicates that the velocity of the water vapor is positively correlated with the wind speed at $10 \mathrm{~m}$ :

$$
v_{\text {water,air }}\left(\mathrm{cm} \mathrm{s}^{-1}\right)=0.2 u_{10}+0.3
$$

where:

$\mathrm{u}_{10}=$ the wind speed at 10 meters above the water surface $\left(\mathrm{m} \mathrm{s}^{-1}\right)$.

The water velocity estimation in air is generally valid between $0{ }^{\circ} \mathrm{C}$ and $25^{\circ} \mathrm{C}$, however the value of $\mathrm{v}_{\text {water,air }}$ is only weakly dependent upon temperature (MacKay and Yeun 1983).

The diffusivity of a given chemical in air can be estimated from the following equation (Fuller et al. 1966):

$$
D_{i a}=10^{-3} \frac{T^{1.75}\left[\left(1 / M_{\text {air }}\right)+\left(1 / M_{i}\right)\right]^{1 / 2}}{p\left[\bar{V}_{\text {air }}^{1 / 3}+\bar{V}_{i}^{1 / 3}\right]^{2}}
$$

where:

$\mathrm{T}=$ Temperature, $\mathrm{K}$

$\mathrm{M}_{\mathrm{air}}=$ the average molar mass for air $\left(\mathrm{g} \mathrm{mol}^{-1}\right)$

$\mathrm{M}_{\mathrm{x}}=$ the chemical molar mass $\left(\mathrm{g} \mathrm{mol}^{-1}\right)$

$\mathrm{p}$ is the gas phase pressure (atmospheric pressure, (atm))

$\bar{V}_{\text {air }}=$ the average molar volume of the gases in air $\left(\mathrm{cm}^{3} \mathrm{~mol}^{-1}\right)$

$\bar{V}_{i}=$ the molar volume for chemical i $\left(\mathrm{cm}^{3} \mathrm{~mol}^{-1}\right)$ 
The water-phase exchange velocity for a given constituent is calculated using a boundary layer model construct (Deacon, 1977) and employing carbon dioxide $\left(\mathrm{CO}_{2}\right)$ as a reference:

$$
v_{\text {water }}\left(\mathrm{cm} \mathrm{s}^{-1}\right)=\left(\frac{S c_{i, w a t e r}}{600}\right)^{a_{S c}} v_{C O 2, \text { water }}
$$

where:

$\mathrm{Sc}_{\mathrm{iw}}=$ the Schmidt number of material $\mathrm{i}$ in water (unitless)

$\mathrm{asc}_{\mathrm{Sc}}=\mathrm{a}$ coefficient that varies as a function of wind speed

$\mathrm{V}_{\mathrm{CO} 2}=$ the water exchange velocity of $\mathrm{CO}_{2}$. $(\mathrm{cm} \mathrm{s}-1)$

The Schmidt number is the ratio of the compounds diffusivity to the kinematic viscosity of the medium it is diffusing through. For the case of chemicals evaporating from the surface, the diffusivity $\left(\mathrm{D}_{\mathrm{x}}\right)$ can be calculated using the following equation:

$$
D_{x}=\frac{13.26 \times 10^{-5}}{\eta^{1.14} \bar{V}_{x}^{0.589}} * 1.0 \times 10^{-4}
$$

where:

$\mathbf{\eta}=$ the dynamic viscosity of the specific chemical material in $\mathrm{cP}$ $\bar{V}_{x}=$ the molar volume of chemical $\mathrm{x},\left(\mathrm{cm}^{3} \mathrm{~mol}^{-1}\right)$

The resulting diffusivity, with the Schmidt number, is used to estimate the aqueous phase transfer velocity. Although Fingas (1999) argued that the air-phase exchange velocity can be effectively ignored due to the fact that oil evaporation is controlled by the diffusivity of the materials in oil, it has been included here for the 
sake of completeness. Table 5 presents the water-controlled (Water Only), air controlled (Air Only), and combined (Water + Air; Water) transfer velocity coefficients for three representative crude oil constituents. In each case presented, the air exchange velocity is significantly faster than the water oil exchange velocity, supporting the case made by (Fingas 2011) that exchange would be water oil limited rather than air limited. The final column in the table calculates the overall exchange using the viscosity of Arabian Light Crude $\left(931 \mathrm{mPa} . \mathrm{s}\right.$ at $20^{\circ} \mathrm{C}$ ) to determine a representative overall transfer coefficient for each of the constituents within crude oil. In all cases, the overall transfer coefficient calculation results in a lower value in crude oil, further supporting the liquid (water or oil) -controlled case. For higher viscosity constituents, the contribution from air exchange begins to become a more significant portion, due to the relatively low diffusivity. 
Table 5: Examples of overall transfer velocity coefficients based on water-controlled exchange (Water Only), Air-controlled exchange (Air only), and the combination of the two for three different crude oil constituents for pure components and within Arabian Light Crude Oil (Oil).

\begin{tabular}{rcccc}
\hline Compound & $\begin{array}{c}\text { Water Only } \\
\text { V }\left(\mathbf{c m ~ s}^{\mathbf{- 1}}\right)\end{array}$ & $\begin{array}{c}\text { Air Only } \\
\left(\mathbf{c m ~ s}^{-\mathbf{1}}\right)\end{array}$ & $\begin{array}{c}\text { Water + Air } \\
\left(\mathbf{c m ~ s}^{\mathbf{- 1}}\right)\end{array}$ & $\begin{array}{c}\text { Water + Air, } \\
\text { Oil }\left(\mathbf{c m ~ s}^{\mathbf{- 1}}\right)\end{array}$ \\
\hline Pentane & 0.0815 & 12.9 & 0.00810 & $1.19 \times 10^{-5}$ \\
Benzene & 0.000922 & 0.0777 & 0.000912 & $1.65 \times 10^{-5}$ \\
Naphthalene & 0.000117 & 0.000463 & 0.0000935 & $1.55 \times 10^{-5}$
\end{tabular}




\section{Application of Heat Budget Information}

Most modeling systems do not implement methods to meticulously account for how much of the available energy that can be used for evaporation is utilized in evaporating materials from the sea surface. By not tracking this information, there is the potential to evaporate oil far more quickly than realistically could be expected. To avoid this potential pitfall, modeling methods were developed to check the energy used for evaporation and balance it according to the available net longwave radiation. Surface net upward longwave radiative flux data for the oceans was acquired from NOAA NCEP/NCAR reanalyzed monthly averaged climatological data (1981-2010) (NOAA/ORA/ESRL PSD). This data is publicly available, and the spatial data resolution is 2.5 degrees. Figure 4 presents global long-term monthly longwave radiative flux data for January (top) and July (bottom). Note the variations in the scales for the figures. The estimated material flux for a given chemical is converted to the energy needed to evaporate it using the chemical specific latent heat of vaporization. The total energy needed is subtracted for the surface area adjusted longwave radiation for the model timestep. When the energy needed exceeds the available energy, the amount of material that can evaporate is reduced to equal the available energy. After this point, no more evaporation can occur for a given particle in the model. The energy requirements for evaporation of a given chemical mass is calculated as:

$$
\text { Energy Required (Joules) }=\text { moles }_{\text {estimated }} \star \Delta H_{\text {vap }}
$$

where: 
moles $_{\text {estimated }}=$ the theoretical amount of material that could be evaporated (moles) $\Delta H_{v a p}=$ the enthalpy of vaporization (joules $\mathrm{mol}^{-1}$ ) for the individual chemical

The energy required to evaporate the amount of a compound is then compared to the area and time-adjusted data from the seasonal profile database, a compilation of geo-referenced set of data that includes temperature, salinity, and values for net longwave radiation at that location as:

$$
\text { Energy Available (Joules) }=L W R_{\text {net }}\left(W m^{-2}\right) \star A r e a_{S U R F}\left(m^{2}\right) * \text { timestep }
$$

The required energy to evaporate material from the oil is subtracted from the total available energy for the slick surface area as the individual components are evaporated. If the required energy exceeds the available energy, the amount of material evaporated is limited as:

$$
\text { Moles }_{E V A P}=\frac{\text { Energy Available }(J)}{\Delta H_{\text {vap }}}
$$

Within the modeling framework, each chemical is subject to chemical specific calculated rates for evaporation. It is not possible to specify the order in which chemicals are queued up to execute the evaporation algorithms within the model. In practice, this means that a less volatile component may be subjected to evaporation within the model before a more volatile component. This does not appear to be a 
Figure 4: Monthly mean surface upward longwave radiation flux $\left(\mathrm{W} \mathrm{m}^{-2}\right)$ for January (top) and July (bottom). Images created from NCEP reanalysis derived data (NOAA/ORA/ESRL PSD)
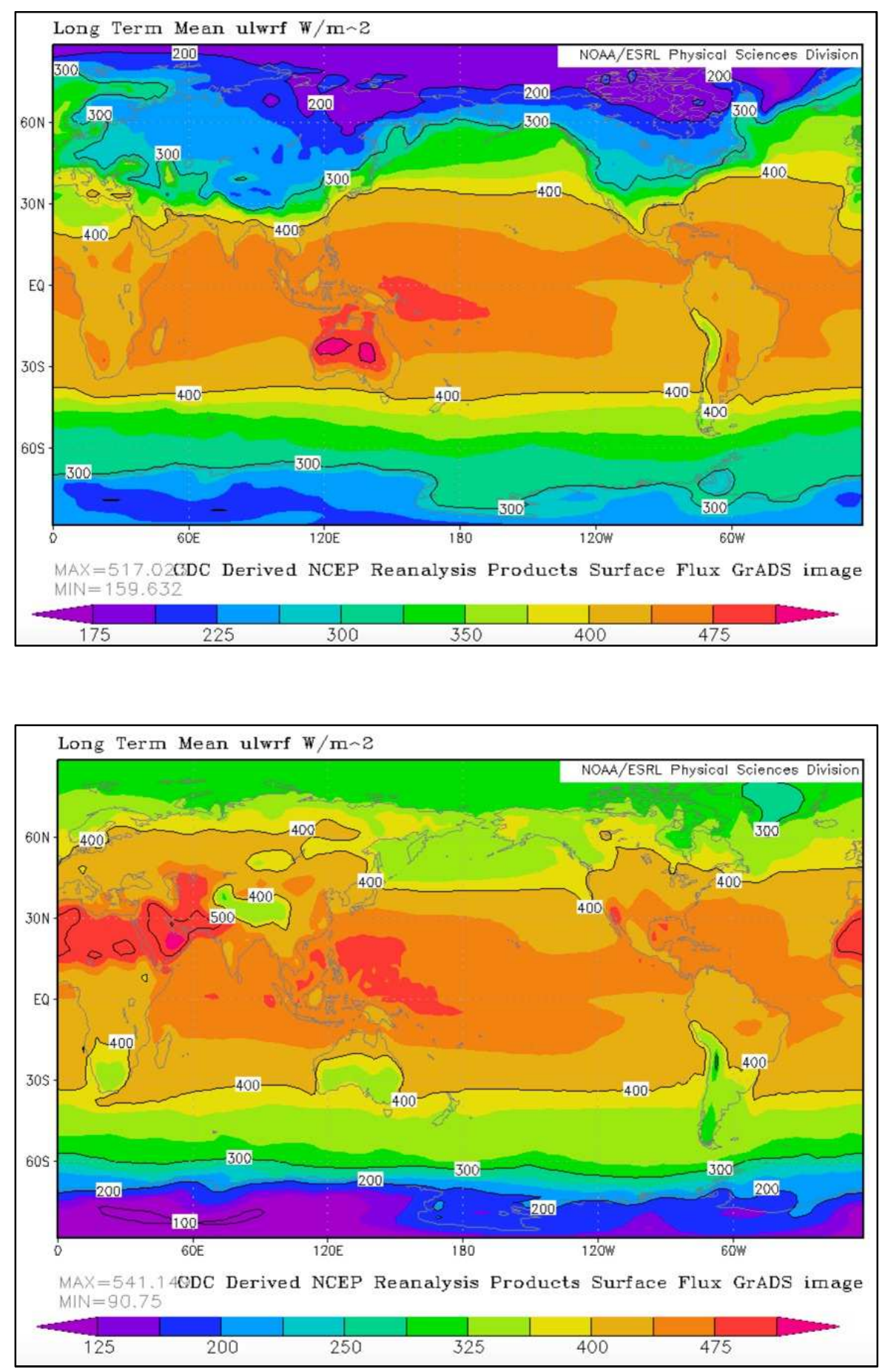
significant problem with model output, as the most volatile components will account for the largest share of energy consumption for evaporation. The result is that the implementation of the energy limitation is minimally impacted by the inability to determine the order of chemical evaporation, due to the theoretical maximum evaporation limit being much smaller for the least volatile components. The theoretical throttling by available energy that would be encountered within the model would thus be applied to the most volatile components that are evaporated first based on the model order. Once they were completely evaporated out of solution, the next most volatile component(s) would no longer be subjected to an energy barrier to evaporate. Generally speaking, after the first few timesteps of a model run, the most volatile components have evaporated out of the crude oil, and there is no longer an energy supply limitation on the overall crude oil evaporative flux.

\section{Slick Spreading}

Once the bulk properties were determined, slick spreading rates were determined using gravitational and viscous forcing. This is accomplished by implementing the original equations of Fay $(1969,1971)$. The length of the slick from the center is determined as a function of time according to the following:

$$
\operatorname{length}(m)=1.5\left[\left(\frac{\rho_{s w}-\rho_{\text {oil }}}{\rho_{s w}}\right) * \frac{A^{2} t^{1.5}}{v^{0.5}}\right]^{0.25}
$$

where:

$\rho_{s w}=$ the density of seawater, or the surrounding water 
$\rho_{\text {oil }}=$ the density of the released oil

$\mathrm{t}=$ time (hours)

$v=$ the kinematic viscosity of the released oil (mPa.s)

$A=$ the maximum surface area of the oil slick, calculated as (Fay 1969):

$$
A\left(m^{2}\right)=10^{5}[V]^{0.75}
$$

where:

$\mathrm{V}=$ the volume of released oil $\left(\mathrm{m}^{3}\right)$

The thickness of the spilled oil is then computed by dividing the volume of oil by the surface area. Although this assumes that the thickness is essentially uniform, the Lagrangian modeling approach applies the thickness calculation on a particle-byparticle basis, so particles of different ages or composition would have different thicknesses.

\section{Emulsification}

The final component of the modeling approach was to use the calculated physical and bulk properties to assess the emulsion state. Fingas (2010) proposed a set of criteria that contribute to the formation of the stability categories of crude oil emulsions. The four general categories of emulsions - stable, meso-stable, entrained, and unstable - vary by viscosity, resin, and asphaltene composition (Figure 5), with some overlap between categories. Stable emulsions can contain up to $80 \%$ water and persist for months to years while unstable emulsions do not contain a significant 
amount of water and do not persist. Fingas further refined this concept and found better agreement between the predicted emulsion state and empirical observations (Fingas 2014).

The time varying bulk properties and the asphaltene: resin ratio from the multicomponent evaporation model were used to characterize a spilled oil relative to the empirical observations (Fingas 2011; M. Fingas 2014). Once the oil was found to be in a stably emulsified state, evaporation ceased to be a major loss term, slick spreading was assumed to be negligible, and, depending on the resulting density, wind-driven surface transport was no longer be applied. Cessation of weathering processes and surface slick drift was implemented as a result of the uncertainty in calculating evaporation due to the presence of water, and the potential for the emulsion to be neutrally buoyant, and thus sub-surface.

The oil emulsion state was determined by calculating a Stability factor (F. Fingas 2014) as follows:

$$
\begin{gathered}
\text { Stability }=5667+9520 * \rho-3.99 * V_{t}+0.138 * S_{t} \mp 0.216 * R_{t} \\
-0.395 * A+17.9 * \frac{A}{R_{t}}+224 * \exp (\rho)+2.88 \times 10^{-10} * \exp \left(R_{t}\right)-4.35 * \\
\exp \left(\frac{A}{R_{t}}\right)+16823 * \ln (\rho)+10.5 * \ln \left(V_{t}\right)-0.671 * \log \left(S_{t}\right)+0.147 * \ln \left(R_{t}\right)+ \\
0.107 * \ln (A)+1.62 * \log \left(\frac{A}{R_{t}}\right)
\end{gathered}
$$

where: 
$S_{t}$ is the transformed saturate content. If the percent saturate content is less that $45 \%$, the value is equal to 45 minus the percent saturate content, otherwise it is the percent saturate content minus 45 .

$R_{t}$ is the transformed resin content. If the percent resin content is less that $10 \%$, the value is equal to 10 minus the percent resin content, otherwise it is the percent resin content minus 10 . If the resin content is equal to zero, this value is set to 20 .

$A_{t}$ is the transformed asphaltene content. If the percent asphaltene content is less that $4 \%$, the value is equal to 4 minus the percent resin content, otherwise it is the percent asphaltene content minus 4 . If the asphaltene content is equal to zero, this value is set to 20 .

$A / \mathrm{R}$ is the asphaltene to resin ratio, calculated as the percent asphaltene divided by the percent resin content $(\mathrm{A} / \mathrm{R})$.

$V_{t}$ is the transformed viscosity, the natural log of the viscosity in (mPa.s).

$\rho$ is the exponential of density $\left(\mathrm{g} \mathrm{mL}^{-1}\right)$.

The computed stability value is compared to the following criteria (

Table 6), and used to determine the oil emulsion state.

Each of these emulsion states has a typical percentage of water and oil, as described in Table 7. These percentages are used to determine density, viscosity, and surface tension of spilled oil when it has weathered but is no longer actively evaporating. Only the "not emulsified" state is subject to all degradation processes and additional surface wind driven transport in the model.

Figure 5 presents the emulsion types graphically as a function of viscosity and the product of resin and asphaltene content. 
The emulsification state algorithm, as implemented in the model, utilizes calculated bulk density and viscosity values that include the impact that calculated changes in these properties have on the individual constituent evaporation rates. By re-determining the bulk properties at each time step, the model affords calculated evaporation rates that can also incorporate changes in the external temperature of the surrounding seawater and the effects that these dynamic rates have on the overall crude oil bulk properties. By implementing the algorithms in this fashion, the emulsification state calculation is also linked to available environmental conditions. 
Table 6: Emulsion state determination matrix, modified from Fingas, 2014

\begin{tabular}{cccc}
\hline $\begin{array}{c}\text { Calculated } \\
\text { Stability Value } \\
\text { Minimum }\end{array}$ & $\begin{array}{c}\text { Calculated } \\
\text { Stability Value } \\
\text { Maximum }\end{array}$ & Other Conditions & State \\
\hline 2.2 & 15 & None & Stable \\
-12 & -0.7 & None & Meso-stable \\
-18.3 & -9.1 & $\begin{array}{c}\text { density }>0.96 \mathrm{~g} \mathrm{~mL}-1 \\
\text { viscosity }>6000 \mathrm{mPa} . \mathrm{s}\end{array}$ & Entrained \\
-7.1 & -39.1 & $\begin{array}{c}\text { density }>0.85 \text { or }<1 \mathrm{~g} \\
\mathrm{~mL}-1\end{array}$ & Unstable \\
& & viscosity $>800000 \mathrm{or}<10$ & \\
& & $\mathrm{mPa} . \mathrm{s}$ &
\end{tabular}


Table 7: Oil and water percentages for the various emulsion states

\begin{tabular}{lcc}
\hline Emulsion State & \% Oil & \% Water \\
\hline Not Emulsified & 100 & 0 \\
Stable & 20 & 80 \\
Meso-Stable & 35 & 65 \\
Unstable & 95 & 5 \\
Entrained & 70 & 30
\end{tabular}


Figure 5: Viscosity and composition ranges for the 4 main emulsion types (Fingas and Lyman, 2011)

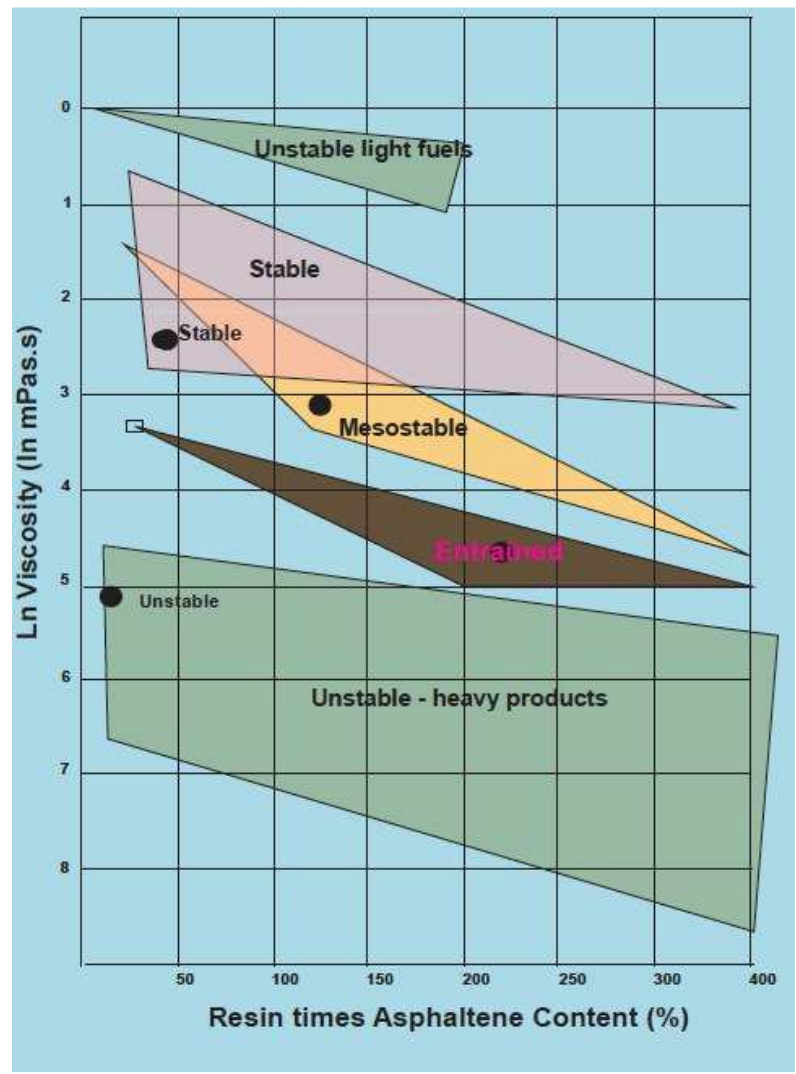




\section{CHAPTER 4}

\section{RESULTS AND DISCUSSION}

The bulk property method calculations described in Chapter 3 were investigated for suitability within the modeling framework. To apply the best possible emulsification state algorithm, the goal for method selection was to best represent empirical data. To that end, the bulk density and bulk viscosity methods were compared to empirical properties and the resulting emulsification state compared to published data (Fingas 2011; Fingas 2014).

\section{Bulk Density Estimates}

Fingas $(2011,2014)$ presented an extensive list of oil compositions with corresponding emulsification states as a function of weathering to test the validity of his emulsification state calculation. The same stability algorithm was implemented within the model proposed in this work. The emulsification state stability algorithm is strongly dependent upon both density and viscosity, and a comparison of the model calculated density to empirical density was done to determine how well the crude oil composition and bulk property calculation represented actual crude oil density. When density data from $25^{\circ} \mathrm{C}$ was not available for the oils investigated, empirical oil densities at $15^{\circ} \mathrm{C}$ in (Fingas 2014) were converted to $25^{\circ} \mathrm{C}$ and compared to estimated crude oil density at $25^{\circ} \mathrm{C}$ using the method of (Manning \& Thompson 1995). The adjustment was done to confirm the composition appropriateness as the majority of density values for individual constituents are reported at $25^{\circ} \mathrm{C}$. This is 
also the case for non-fitted viscosity data. Density and viscosity at two temperatures can then be used to estimate viscosity at a third temperature when empirical information is unavailable. Density values at $25^{\circ} \mathrm{C}$ were calculated using Manning and Thompson's method (Equation 11). Crude oil API values ranged from extra heavy $\left(\right.$ API $<10$, density $\left.>1000 \mathrm{~kg} \mathrm{~m}^{-3}\right)$ to extra light $\left(\right.$ API $>40$, density $\left.<825 \mathrm{~kg} \mathrm{~m}^{-3}\right)$.

Empirical or temperature adjusted density for non-weathered oils was then compared to model calculated density. Figure 6 shows the preliminary regression fit for model predicted values versus the reported density values for 110 different unweathered oils. The equation for the linear regression of the model predicted density values versus empirical density values suggests that using the generic oil composition list and varying the percentages of the saturates, aromatics, resins, and asphaltenes can represent crude oil density values fairly well $\left(\mathrm{R}^{2}=0.90083\right.$, Figure 6$)$. The initially proposed saturate content generally under predicted crude oil density for lower density crude oils, but showed a slightly better fit for higher density crude oils, where the aromatic, resin, and asphaltene amounts in the crude oils were somewhat higher.

To investigate improving the fit between empirical and model calculated density values, the relative composition of the saturate content was modified to shift towards higher molecular weight compounds. The preliminary composition resulted in an average saturate density value of $727 \mathrm{~kg} \mathrm{~m}^{-3}$. A shift in composition towards decreased content below C6 hydrocarbons resulted in an average saturate density of 
$749 \mathrm{~kg} \mathrm{~m}^{-3}$. A linear regression of the modified saturate content predicted density compared to the empirical density value (

Figure 7) showed no improvement in the correlation coefficient for the linear regression of the actual density versus model-calculated density, however the distribution of data at both low and high density ranges showed model predictions that were both greater and less than the empirical data, presumably resulting in a better overall fit of the data, with the slope of the linear fit of the modified saturate content somewhat closer to 1 ( 0.8886 vs. 0.8257$)$. Another iteration of composition modifications in the saturate content towards a slightly more dense composition (Figure 8) showed a slope closer to unity (0.9847) with an intercept of 0.0146. A comparison of actual and predicted values using the slope and intercepts for each of the three saturate density linear fit regression equations (Tab le 8) suggests that the highest density saturate composition results in data closer to anticipated results - i.e. the resulting density agrees better with empirical values for the crude oils examined when assigning the initial, empirical density as the independent variable and calculating the expected density. The relative error in the slope of the three separate iterations was assessed in an attempt to identify the best overall fit, however the results were essentially the same $(3.5 \%-3.6 \%)$.

The results indicate that, overall, the density values that result from assigning component fraction percentages agree reasonably well with observations: Relative errors in the density calculations were generally less than $5 \%$, with model calculations over and under predicting oil bulk density values (Table 6). The final generic crude oil 
composition with relative percentages within each major component class is presented in Appendix 1. 
Figure 6: Comparison of actual oil density and model predicted density ( $\mathrm{g} / \mathrm{mL}$ ) for unweathered oils. Saturate density $0.727 \mathrm{~g} \mathrm{~mL}^{-1}$. The dark line in the figure is the ideal slope of a linear fit of unity. The relative error of the slope and intercept are $3.3 \%$ and $26.7 \%$, respectively.

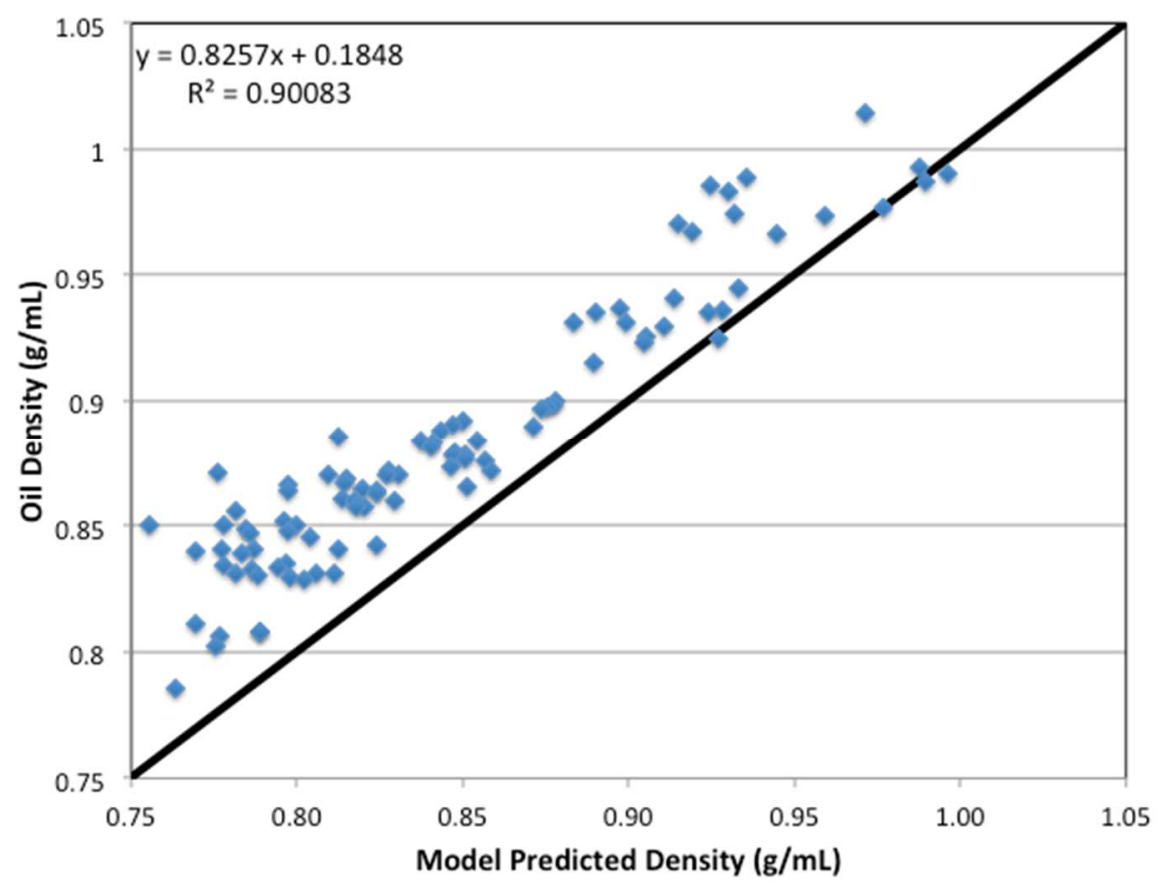


Figure 7: Comparison of actual oil density and model predicted density ( $\mathrm{g} / \mathrm{mL}$ ) for unweathered oils. Saturate density $0.749 \mathrm{~g} \mathrm{~mL}^{-1}$. The dark line in the figure is the ideal slope of a linear fit of unity. The relative error of the slope and intercept are $3.4 \%$ and $74.5 \%$, respectively.

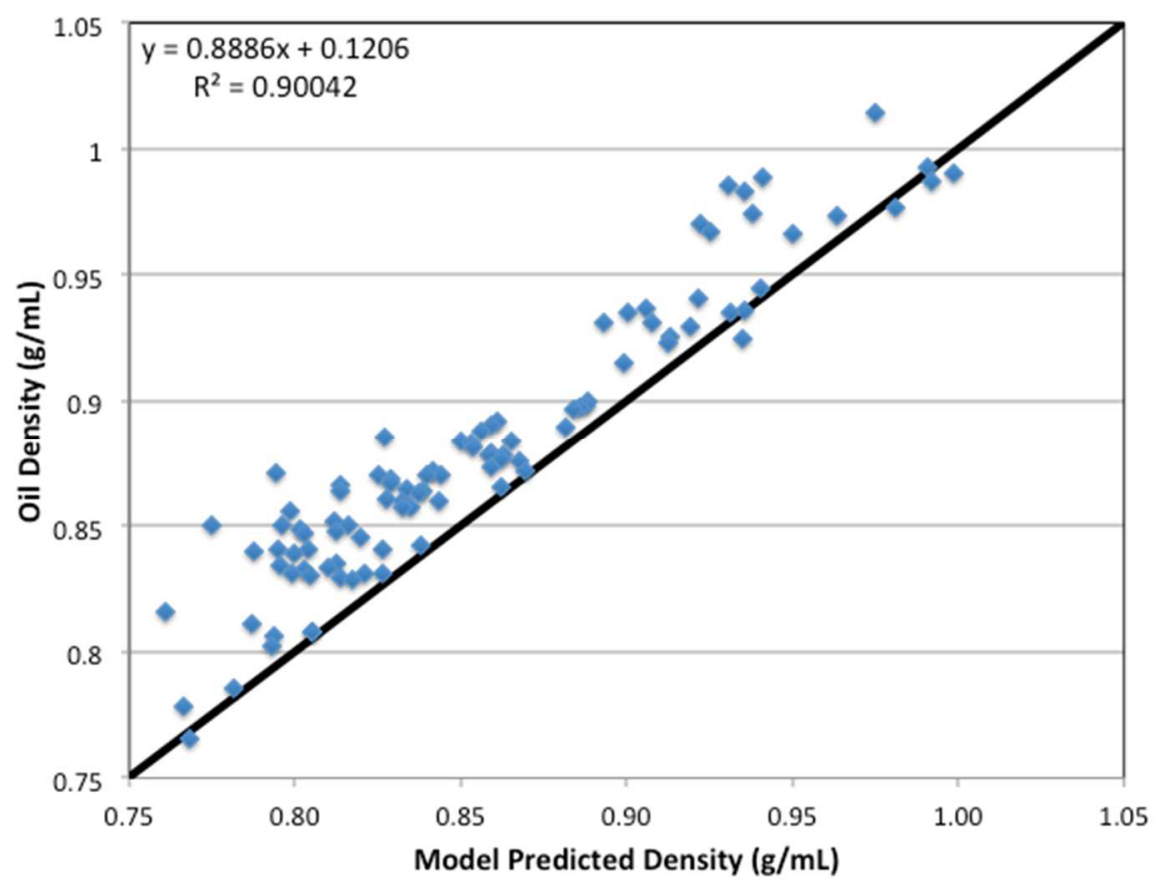


Figure 8: Comparison of actual oil density and model predicted density ( $\mathrm{g} / \mathrm{mL}$ ) for unweathered oils. Saturate density $0.780 \mathrm{~g} \mathrm{~mL}^{-1}$. The dark line in the figure is the ideal slope of a linear fit of unity. The relative error of the slope and intercept are $3.4 \%$ and $36.6 \%$, respectively.

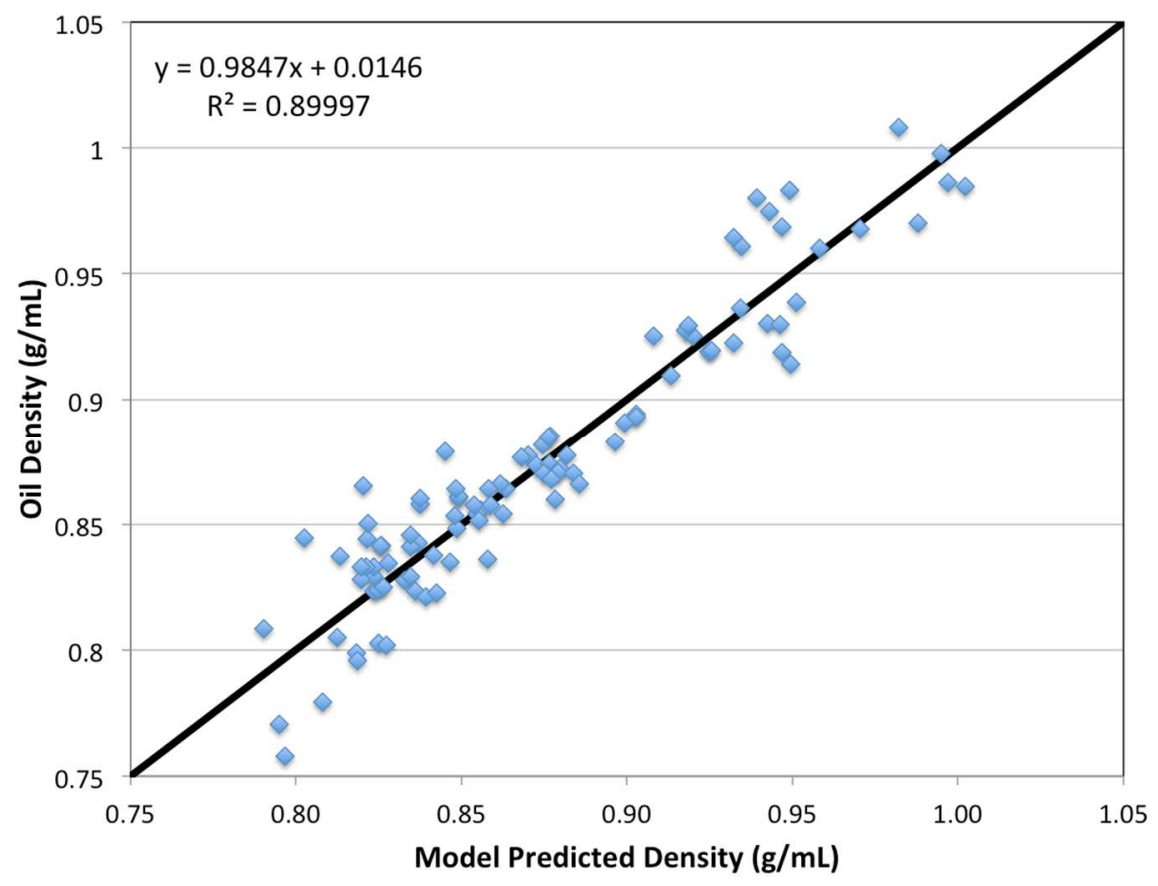


Table 8: Comparison of model predicted density for each of the saturate density values using the resultant linear least square slope and intercept. The adjusted saturate density of $780 \mathrm{~kg} \mathrm{~m}^{-3}$ showed the best overall fit across a range of crude oil densities.

\begin{tabular}{lccc}
\hline & $\begin{array}{c}\text { Saturate } \\
\text { Density } \\
\mathbf{7 2 7} \\
\left(\mathbf{k g ~ m}^{-3}\right)\end{array}$ & $\begin{array}{c}\text { Saturate } \\
\text { Density } \\
\mathbf{7 4 9} \\
\left(\mathbf{k g ~ m}^{-3}\right)\end{array}$ & $\begin{array}{c}\text { Saturate } \\
\text { Density } \\
\mathbf{7 8 0} \\
\left.\mathbf{( k g ~ m}^{-3}\right)\end{array}$ \\
\hline Calculated Density, Actual Density $=750 \mathrm{~kg} \mathrm{~m}^{-3}$ & 804 & 787 & 753 \\
Calculated Density, Actual Density $=800 \mathrm{~kg} \mathrm{~m}^{-3}$ & 845 & 831 & 802 \\
Calculated Density, Actual Density $=850 \mathrm{~kg} \mathrm{~m}^{-3}$ & 887 & 876 & 851 \\
Calculated Density, Actual Density $=900 \mathrm{~kg} \mathrm{~m}^{-3}$ & 928 & 920 & 900 \\
Calculated Density, Actual Density $=950 \mathrm{~kg} \mathrm{~m}^{-3}$ & 969 & 965 & 950 \\
Calculated Density, Actual Density $=1000 \mathrm{~kg} \mathrm{~m}^{-3}$ & 1011 & 1009 & 999
\end{tabular}


Table 9: Comparison of model calculated density to a subset of empirical density data from (Fingas 2011; Fingas 2014)

\begin{tabular}{|c|c|c|c|c|c|}
\hline Oil & Saturate \% & Resin \% & Asphaltene \% & $\begin{array}{c}\text { Density } \\
\text { empirical } \\
\left(\mathrm{kg} \mathrm{m}^{-3}\right) \\
\end{array}$ & $\begin{array}{l}\text { Density } \\
\text { (model) } \\
\left(\mathrm{kg} \mathrm{m}^{-3}\right)\end{array}$ \\
\hline Arabian Light & 51 & 6 & 3 & 859.9 & 878.3 \\
\hline Arabian Med & 55 & 7 & 6 & 872.4 & 879.7 \\
\hline Canolimon & 60 & 8 & 8 & 873.8 & 872.5 \\
\hline Hondo & 33 & 24 & 12 & 929.7 & 946.2 \\
\hline Lago Treco & 38 & 14 & 11 & 917.1 & 924.7 \\
\hline Lucula & 62 & 9 & 4 & 851.5 & 855.3 \\
\hline Neptune Spar & 58 & 19 & 10 & 861.3 & 849.2 \\
\hline Platform Gail & 39 & 21 & 12 & 922.4 & 932.1 \\
\hline $\begin{array}{l}\text { Point Arguello } \\
\text { Comingled }\end{array}$ & 36 & 23 & 16 & 918.9 & 946.8 \\
\hline Sockeye & 48 & 13 & 8 & 890.6 & 899.4 \\
\hline $\begin{array}{l}\text { Sockeye } \\
\text { Comingled }\end{array}$ & 34 & 21 & 13 & 930.3 & 942.4 \\
\hline Sockeye Sour & 38 & 20 & 13 & 936.2 & 935.1 \\
\hline Takula & 65 & 8 & 2 & 857.8 & 858.7 \\
\hline MC 807 & 47 & 12 & 6 & 883.0 & 896.4 \\
\hline $\begin{array}{l}\text { Prudhoe Bay } \\
1995\end{array}$ & 53 & 10 & 4 & 877.8 & 881.8 \\
\hline Santa Clara & 36 & 29 & 13 & 914.3 & 949.3 \\
\hline Sockeye 2000 & 50 & 18 & 15 & 929.5 & 918.4 \\
\hline
\end{tabular}




\section{Bulk Viscosity Predictions}

The mass-weighted chemical constituent viscosity values were tested to derive a composite bulk viscosity for crude oil using the identified subset of constituent chemicals. A comparison of the calculated values to empirical data from (Fingas 2011; Fingas 2014)(

Table 10) showed very poor agreement for oils with resin content above $14 \%$. This is partly due to the complex interaction of asphaltenes with the aromatic components in oil, an area that is still under active investigation. It is also the result of the overly simplistic approach using mass-weighted fractional contributions for calculating bulk viscosity.

Although altering the viscosity of the resin constituent to match the derived data would seem to resolve the problem for the grossest discrepancies in viscosity, as is the case for Santa Clara and Sockeye 2000 crude oils, this resulted in an increase in the discrepancy for lower viscosity oils. Also, in scrutinizing the results, the model predicted result for Arabian Light and Arabian Medium crude oil suggest that the discrepancy is in the calculation of the saturate contribution to the bulk viscosity. The saturate percentages for Arabian Light and Arabian Medium crude oil respectively, are $51 \%$ and $55 \%$, with actual viscosity values of 9.1 and $19.5 \mathrm{mPa} . \mathrm{s}$. The model calculated viscosity results in Arabian Medium with a slightly lower viscosity of 24.2 mPa.s than Arabian Light (29.7), the opposite of the empirical results. It is possible that one or more of the saturate constituents has an error in the fitted viscosity 
coefficients, resulting in the inconsistent value being amplified with increasing saturate content.

The Beal method (Beal, 1970) was also tested to calculate dead oil viscosity $(\mu)$ as a function of temperature $\left(\mathrm{T},{ }^{\circ} \mathrm{F}\right)$ and API gravity based on the adjusted crude oil density. Table 10 and

Figure 9 present empirical data and the simple bulk viscosity calculation and the Beal method to the published empirical viscosity values. The Beal method performed better than the simple method for the highest density oils, but did not perform better than the simple method for high API gravity values (low density) oils based on a linear regression of the predicted and empirical data. Implementation of the Beal method did not resolve the viscosity discrepancies for Sockeye 2000 that are largely the reason that the model predicts the formation of a stable emulsion (Table 11).

Table 10 also contains the friction theory viscosity methodology results. This method does a better job at matching higher viscosity oil than the simple massweighted approach, providing a moderate means for estimating viscosity that can match lower and moderate viscosities well. The fact that it is based on constituent properties, assuming they are well represented, argues for using the friction viscosity method over the Beal method, although the Beal results show a reasonable fit for the subset of data investigated.

Table 11 presents a comparison of the observed and model predicted emulsion states for the subset of oils investigated. The model replicated observed emulsification states in 14 of the 17 oils investigated. Discrepancies in the timing of the onset of 
emulsification are discussed in the next section. The observed results suggest that the proposed model, even with the observed discrepancies in viscosity, is useful for predicting the ultimate emulsification state. 
Table 10: Oil characterization and comparison of model calculated mass-weighted viscosity, viscosity calculated using the linear friction theory approach, and empirical viscosity data from (Fingas 2011; M. F. Fingas 2014; Environment Canada)

\begin{tabular}{|c|c|c|c|c|c|c|c|c|}
\hline Oil & $\begin{array}{c}\text { API } \\
\text { Gravity }\end{array}$ & Saturate\% & Aromatic\% & Resin\% & $\begin{array}{c}\text { Viscosity } \\
\text { Fingas } \\
\text { (mPa.s) }\end{array}$ & $\begin{array}{l}\text { Viscosity } \\
\text { Simple } \\
\text { Model } \\
\text { (mPa.s) }\end{array}$ & $\begin{array}{c}\text { Viscosity } \\
\text { Beal } \\
\text { Method } \\
\text { (mPa.s) }\end{array}$ & $\begin{array}{c}\text { Viscosity } \\
\text { Friction } \\
\text { Theory } \\
\text { (mPa.s) }\end{array}$ \\
\hline Arabian Light & 31.9 & 51 & 39 & 6 & 9.1 & 29.7 & 27.9 & 64.7 \\
\hline Arabian Medium & 29.6 & 55 & 32 & 7 & 19.5 & 24.2 & 39.2 & 75.4 \\
\hline Canolimon & 29.0 & 60 & 24 & 8 & 25 & 18.7 & 43.1 & 59.5 \\
\hline Hondo & 19.7 & 33 & 31 & 24 & 317.2 & 22.6 & 58.6 & 128.0 \\
\hline Lago Treco & 21.8 & 37 & 38 & 14 & 169 & 27.4 & 155.8 & 105.6 \\
\hline Lucula & 33.5 & 66 & 22 & 9 & 13.3 & 18.5 & 22.4 & 52.6 \\
\hline Neptune Spar & 21.6 & 65 & 28 & 19 & 13 & 10.8 & 163.5 & 58.9 \\
\hline Platform Gail & 20.7 & 39 & 28 & 21 & 196 & 20.8 & 58.6 & 118 \\
\hline Arguello & 21.5 & 36 & 25 & 23 & 233 & 18.7 & 165.8 & 126.9 \\
\hline Sockeye 1995 & 26.3 & 48 & 31 & 13 & 27.2 & 23.2 & 66.4 & 91.2 \\
\hline Sockeye Comingled & 19.8 & 34 & 32 & 21 & 310 & 23.4 & 238.9 & 133.4 \\
\hline Sockeye Sour & 18.9 & 38 & 29 & 20 & 470 & 21.5 & 298.3 & 120 \\
\hline Takula & 32.3 & 65 & 22 & 8 & 19.3 & 18.02 & 26.4 & 58.6 \\
\hline MC 807 & 27.6 & 47 & 35 & 12 & 29 & 22.5 & 53.8 & 93.7 \\
\hline Prudhoe Bay 1995 & 28.6 & 52 & 34 & 10 & 14.7 & 25.3 & 45.7 & 82.5 \\
\hline Santa Clara & 22.3 & 36 & 22 & 29 & 141.3 & 330 & 141.6 & 135.3 \\
\hline Sockeye 2000 & 19.8 & 49.2 & 17.2 & 15.1 & 346.9 & $411.5^{*}$ & 242.5 & 110 \\
\hline
\end{tabular}

- Asphaltene viscosity altered in an attempt to replicate viscosity. 
Figure 9: Comparison of Actual Viscosity Values (Fingas) and Model Predicted Viscosity values (mPa.s) for the three methods of bulk viscosity calculations. The dark line in the figure represents a perfect fit between empirical and calculated viscosity.

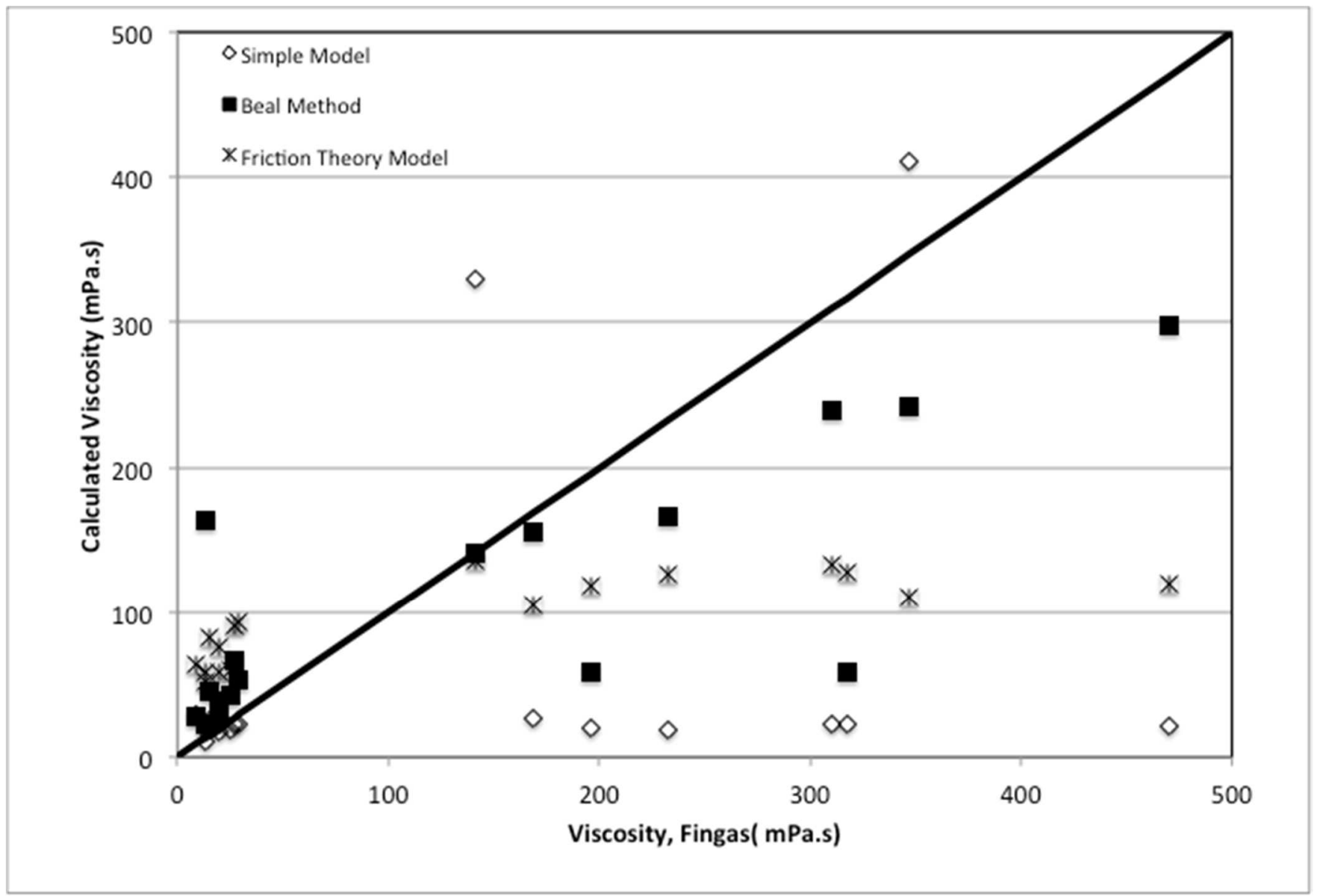


Table 11: Comparison of model calculated emulsification state prediction to empirical emulsion state observations from (Fingas 2011; M. F. Fingas 2014; Environment Canada).

\begin{tabular}{ccccccc}
\hline Oil & $\begin{array}{c}\text { Saturate } \\
\mathbf{\%}\end{array}$ & $\begin{array}{c}\text { Aromatic } \\
\mathbf{\%}\end{array}$ & $\begin{array}{c}\text { Resin } \\
\mathbf{\%}\end{array}$ & $\begin{array}{c}\text { Asphaltene } \\
\mathbf{\%}\end{array}$ & $\begin{array}{c}\text { Emulsion } \\
\text { State, Fingas }\end{array}$ & $\begin{array}{c}\text { Emulsion State, } \\
\text { Model }\end{array}$ \\
\hline Arabian Light & 51 & 39 & 6 & 3 & STABLE & UNSTABLE \\
Arabian Med & 55 & 32 & 7 & 6 & STABLE & STABLE \\
Canolimon & 60 & 24 & 8 & 8 & STABLE & STABLE \\
Hondo & 33 & 31 & 24 & 12 & STABLE & STABLE \\
Lago Treco & 37 & 38 & 14 & 11 & STABLE & STABLE \\
Lucula & 66 & 22 & 9 & 4 & STABLE & STABLE \\
Neptune Spar & 65 & 28 & 19 & 10 & STABLE & STABLE \\
Platform Gail & 39 & 28 & 21 & 12 & STABLE & STABLE \\
Arguello & 36 & 25 & 23 & 16 & STABLE & STABLE \\
Sockeye 1995 & 48 & 31 & 13 & 8 & STABLE & STABLE \\
Sockeye Comingled & 34 & 32 & 21 & 13 & STABLE & STABLE \\
Sockeye Sour & 38 & 29 & 20 & 13 & STABLE & STABLE \\
Takula & 65 & 22 & 8 & 2 & STABLE & STABLE \\
MC 807 & 47 & 35 & 12 & 6 & MESOSTABLE & STABLE \\
Prudhoe Bay 1995 & 52 & 34 & 10 & 4 & MESOSTABLE & STABLE \\
Santa Clara & 36 & 22 & 29 & 13 & MESOSTABLE & MESOSTABLE \\
Sockeye 2000* & 49.2 & 17.2 & 15.1 & 18.5 & MESOSTABLE & STABLE
\end{tabular}




\section{Weathering Rates}

The most comprehensive test of the proposed model's ability to accurately determine the fate and transport of spilled oil and capture emulsion state is to compare the model predicted weathering to empirical data. This comparison consisted of model output over the time period of interest and information from the Environment Canada oil spill database (ref). Model estimated changes in crude oil bulk properties as a function of oil weathering state were compared to empirical data for several different oil types to test the model's overall ability to replicate observed crude oil weathering. The output density, mass, viscosity, and emulsification states were compared to documented laboratory data for 4 different oils: Arabian Light Crude Oil, Hondo Crude Oil, Santa Clara Crude Oil, and Jet Fuel.

Table 12 shows an abbreviated comparison of empirical data and model predicted Arabian Light crude oil properties at 3 stages of weathering. The mass of Arabian Light as a function of time as predicted by the model and the Environment Canada fitted data are presented in Figure 10. The model under-predicts the evaporation rate during the first hour: $8 \%$ model predicted vs. $\sim 12 \%$ empirical fitted value. The model tracks reasonably well with empirical data for the first 7-8 hours, but after this point the model does not capture the transition to a stable emulsion, and therefore evaporation continues without the dampening effect observed for mesostable and stable emulsions. The model over-predicts the viscosity in the nonemulsified oil, and under-predicts the viscosity in the stably emulsified oil. Part of the under-prediction is a function of the time-dependent algorithm implemented for meso- 
stable emulsion viscosity, suggesting that this algorithm should be revisited.

Additionally, the model predicts an unstable emulsification state for Arabian Light, whereas the empirical data suggest a stable emulsion is formed.

Hondo crude oil was also used to compare model predictions to empirical data. Model output shows comparable results for time to evaporation. The model predicts $17 \%$ weathering of Hondo crude at 6 hours, whereas empirical results suggest 17\% weathering is reached at 11 hours (Table 13, Figure 11). The fitted equation predicts $34 \%$ oil weathering at 134 hours. The model does not achieve $34 \%$ weathering of the oil because the evaporation algorithms are not implemented within the model once a stable emulsion forms. The weathered viscosity values show better agreement for the partially weathered oil than for the Arabian Light crude, but the implemented viscosity algorithm under-predicted the weathered oil viscosity again. This may be due to the inability to select the evaporation order in the model, causing an under-prediction of the initial calculated evaporation rate. Density values show reasonable agreement between model predictions and empirical observations.

A comparison of Santa Clara crude model predictions with empirical data shows reasonable agreement for un-weathered and moderately weathered (11\%) oil, with the model capturing the meso-stable emulsion state at $11 \%$ weathering (Table 14 , Figure 12). For Santa Clara crude oil, the model predicts a stable emulsion earlier than it is achieved. The final state of weathered Santa Clara oil is a stable emulsion (Fingas 2014), however empirical data from Environment Canada show a meso-stable 
emulsion at $22 \%$ weathering. The model determined a stable emulsification state when the weathering corresponded to $14 \%$.

The weathering of Jet Fuel was well captured by the model formulation, with $53 \%$ weathering achieved within 2.5 hours of the anticipated weathering rate from the Environment Canada empirical observations: The model required roughly 26.5 hours to reach $53 \%$ weathering, whereas the equation derived from empirical data suggested 24.25 hours to reach $53 \%$ weathering of the material. The Jet Fuel was comprised of only saturates and resins, yet the predicted viscosity values were still larger than the empirical results, further reinforcing the possibility of an error in a saturate constituent viscosity value. 
Table 12. Comparison of observed and model predicted density, viscosity, and emulsification state for Arabian Light crude oil. Observed density and viscosity values were converted to $25^{\circ} \mathrm{C}$ for temperature corrected comparison.

\begin{tabular}{|c|c|c|c|c|c|c|c|}
\hline $\begin{array}{c}\text { Observed \% } \\
\text { Evaporated } \\
\text { (time to reach } \\
\%, \text { hr) } \\
\end{array}$ & $\begin{array}{c}\text { Model \% } \\
\text { Evaporated } \\
\text { (time to } \\
\text { reach \%, hr) }\end{array}$ & $\begin{array}{c}\text { Actual } \\
\text { Density } \\
\left(\mathrm{kg} \mathrm{m}^{-3}\right) \\
\end{array}$ & $\begin{array}{c}\text { Model } \\
\text { Density } \\
\left(\mathrm{kg} \mathrm{m}^{-3}\right) \\
\end{array}$ & $\begin{array}{c}\text { Actual } \\
\text { Viscosity } \\
\text { (mPa.s) } \\
\end{array}$ & $\begin{array}{c}\text { Model } \\
\text { Viscosity } \\
\text { (mPa.s) } \\
\end{array}$ & $\begin{array}{c}\text { Actual } \\
\text { Emulsion State }\end{array}$ & $\begin{array}{c}\text { Model } \\
\text { Emulsion } \\
\text { State } \\
\end{array}$ \\
\hline $0 \%(0)$ & $0 \%(0)$ & 859.9 & 859.9 & 9.2 & 64.7 & NONE & NONE \\
\hline $12 \%(0.54)$ & $12 \%(1)$ & 886.2 & 881.4 & 46000 & 9100 & STABLE & STABLE \\
\hline $24 \%(17.7)$ & N/A & 905.2 & 896 & 48000 & N/A & STABLE & STABLE \\
\hline
\end{tabular}


Table 13: Comparison of observed and model predicted density, viscosity, and emulsification state for Hondo crude oil. Observed density and viscosity values were converted to $25^{\circ} \mathrm{C}$ for temperature corrected comparison.

\begin{tabular}{|c|c|c|c|c|c|c|c|}
\hline $\begin{array}{c}\text { Observed \% } \\
\text { Evaporated } \\
\text { (time to reach } \\
\%, \text { hr) }\end{array}$ & $\begin{array}{c}\text { Model \% } \\
\text { Evaporated } \\
\text { (time to } \\
\text { reach \%, hr) }\end{array}$ & $\begin{array}{c}\text { Actual } \\
\text { Density } \\
\left(\mathrm{kg} \mathrm{m}^{-3}\right)\end{array}$ & $\begin{array}{c}\text { Model } \\
\text { Density } \\
\left(\mathrm{kg} \mathrm{m}^{-3}\right)\end{array}$ & $\begin{array}{c}\text { Actual } \\
\text { Viscosity } \\
\text { (mPa.s) }\end{array}$ & $\begin{array}{c}\text { Model } \\
\text { Viscosity } \\
\text { (mPa.s) }\end{array}$ & $\begin{array}{c}\text { Actual Emulsion } \\
\text { State }\end{array}$ & $\begin{array}{c}\text { Model Emulsion } \\
\text { State }\end{array}$ \\
\hline $0 \%(0)$ & $0 \%(0)$ & 929.67 & 937.7 & 341.2 & 128.0 & NONE & NONE \\
\hline $17 \%(11)$ & $14 \%(6)$ & 961.47 & 1017.15 & 2650 & 1850 & STABLE & STABLE \\
\hline $32 \%(143)$ & N/A & 982.17 & N/A & 937.7 & N/A & STABLE & STABLE \\
\hline
\end{tabular}


Table 14. Comparison of observed and model predicted density, viscosity, and emulsification state for Santa Clara crude oil. Observed density and viscosity values were converted to $25^{\circ} \mathrm{C}$ for temperature corrected comparison.

\begin{tabular}{|c|c|c|c|c|c|c|c|}
\hline $\begin{array}{c}\text { Observed \% } \\
\text { Evaporated } \\
\text { (time to reach } \\
\%, \text { hr) }\end{array}$ & $\begin{array}{c}\text { Model \% } \\
\text { Evaporated } \\
\text { (time to } \\
\text { reach \%, hr) }\end{array}$ & $\begin{array}{c}\text { Actual } \\
\text { Density } \\
\left(\mathrm{kg} \mathrm{m}^{-3}\right)\end{array}$ & $\begin{array}{c}\text { Model } \\
\text { Density } \\
\left(\mathrm{kg} \mathrm{m}^{-3}\right)\end{array}$ & $\begin{array}{c}\text { Actual } \\
\text { Viscosity } \\
\text { (mPa.s) }\end{array}$ & $\begin{array}{l}\text { Model } \\
\text { Viscosity } \\
\text { (mPa.s) } \\
\end{array}$ & $\begin{array}{c}\text { Actual Emulsion } \\
\text { State }\end{array}$ & $\begin{array}{c}\text { Model Emulsion } \\
\text { State }\end{array}$ \\
\hline $0 \%(0)$ & $0 \%(0)$ & 914.3 & 939.6 & 141.3 & 135.3 & NONE & NONE \\
\hline $11 \%(0.92)$ & $11 \%(1.5)$ & 942.0 & 954.6 & 516 & 189.2 & MESO & MESO \\
\hline $22 \%(143)$ & N/A & 961.3 & 954.6 & $13105^{*}$ & 1200 & MESO & STABLE \\
\hline
\end{tabular}

*Estimated from $10 \mathrm{~m} / \mathrm{s}$ shear rate data for 0 and $15^{\circ} \mathrm{C}$ 
Table 15. Comparison of observed and model predicted density, viscosity, and emulsification state for Anchorage Jet-Fuel. Observed density and viscosity values were converted to $25^{\circ} \mathrm{C}$ for temperature corrected comparison.

\begin{tabular}{cccccccc}
\hline $\begin{array}{c}\text { Observed \% } \\
\text { Evaporated } \\
\text { (time to reach } \\
\% \text {, hr) }\end{array}$ & $\begin{array}{c}\text { Model \% } \\
\text { Evaporated } \\
\text { (time to } \\
\text { reach \%, hr) }\end{array}$ & $\begin{array}{c}\text { Actual } \\
\text { Density } \\
\left(\mathbf{k g ~ m}^{-3}\right)\end{array}$ & $\begin{array}{c}\text { Model } \\
\text { Density } \\
\left.\mathbf{( k g ~ m}^{-3}\right)\end{array}$ & $\begin{array}{c}\text { Actual } \\
\text { Viscosity } \\
(\mathbf{m P a . s})\end{array}$ & $\begin{array}{c}\text { Model } \\
\text { Viscosity } \\
(\mathbf{m P a . s})\end{array}$ & $\begin{array}{c}\text { Actual Emulsion } \\
\text { State }\end{array}$ & $\begin{array}{c}\text { Model Emulsion } \\
\text { State }\end{array}$ \\
\hline $0 \%(0)$ & $0 \%(0)$ & 805 & 778 & 2 & 38 & NONE & NONE \\
$53 \%(24.25)$ & $53 \%(26.5)$ & 829 & 785 & 4 & 20 & NONE & NONE
\end{tabular}


Figure 10: Comparison of laboratory predicted evaporation curve and model predicted evaporation during the first 48 hours for Arabian Light crude oil. Inset picture displays results for the first 6 hours.

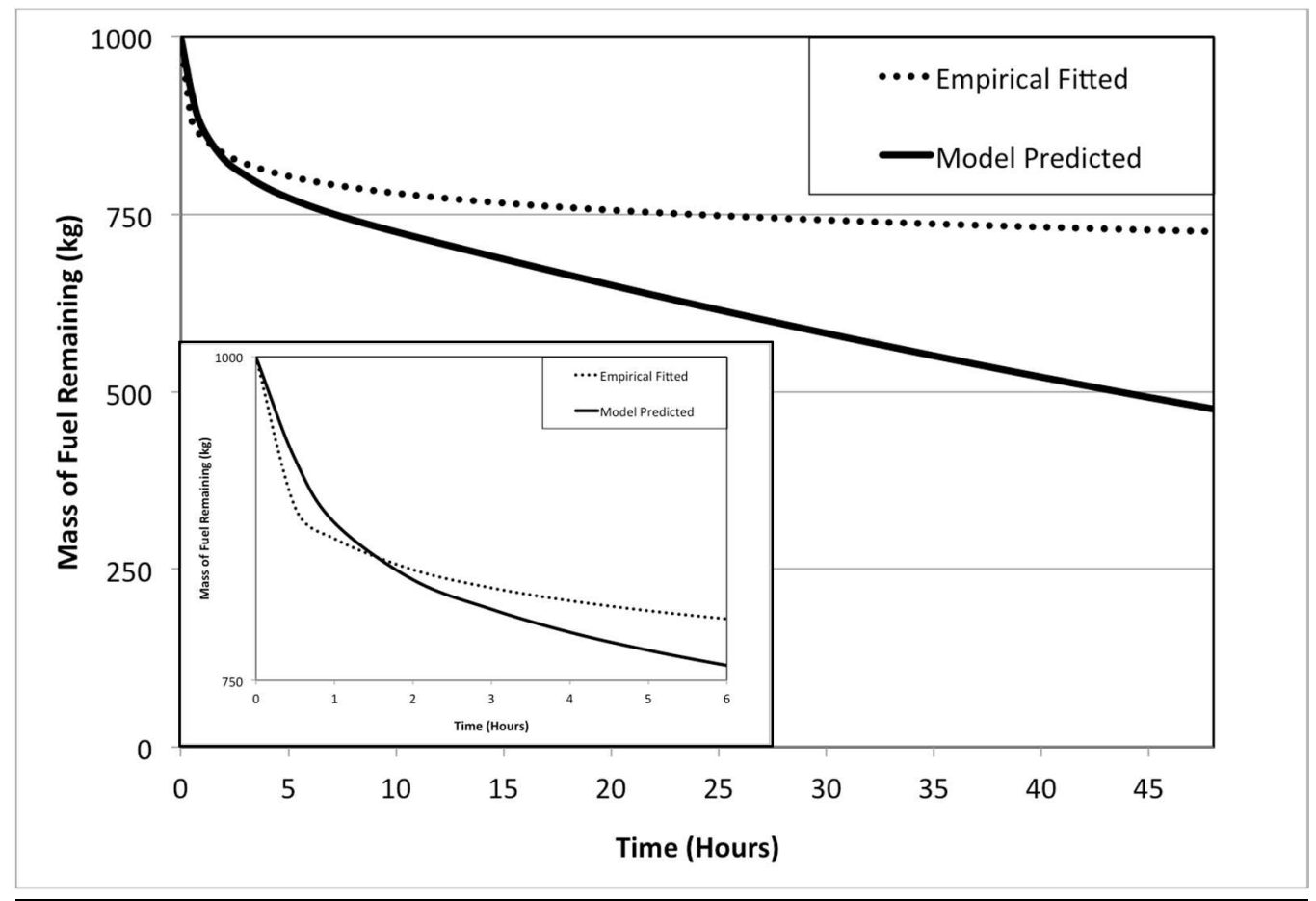


Figure 11: Comparison of laboratory predicted evaporation curve and model predicted evaporation during the first 48 hours for Hondo crude oil. Inset picture displays results for the first 6 hours.

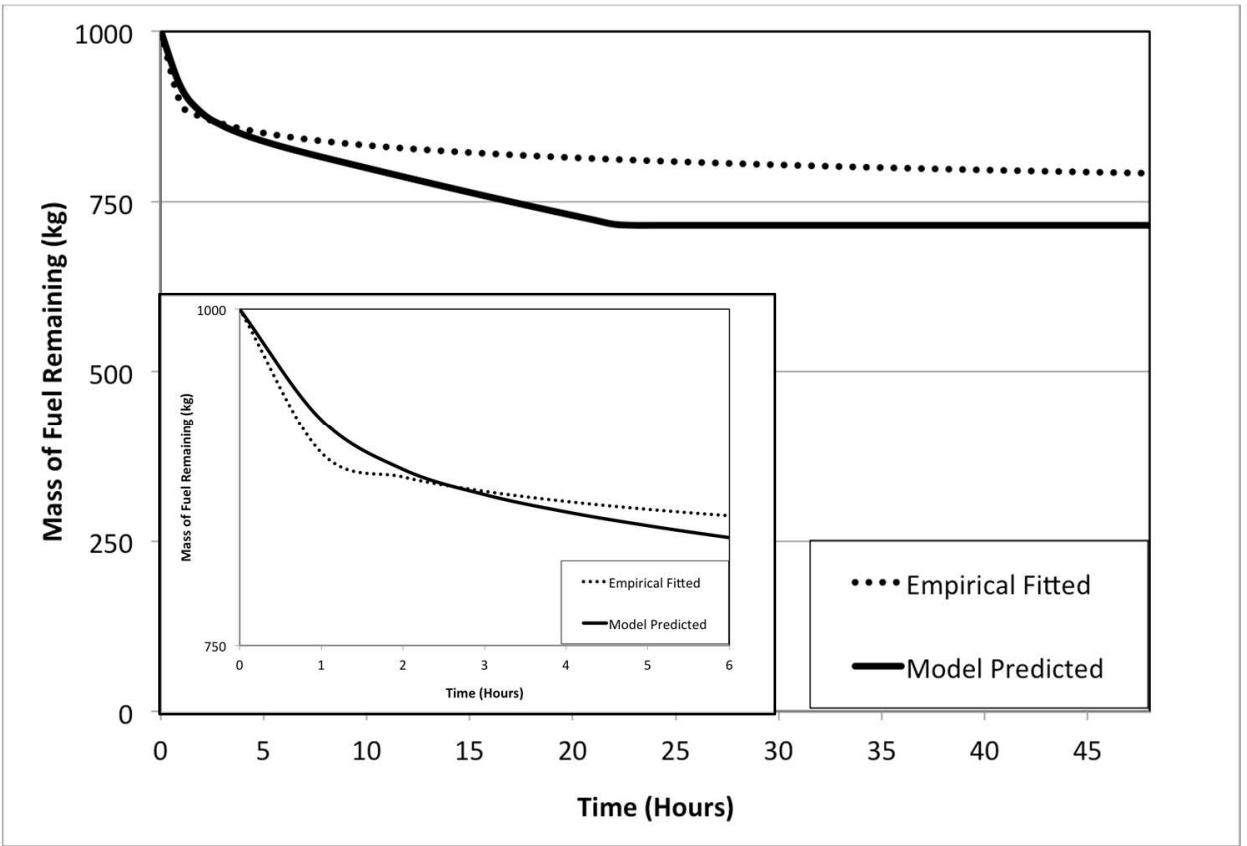


Figure 12: Comparison of laboratory predicted evaporation curve and model predicted evaporation during the first 48 hours for Santa Clara crude oil. Inset picture displays results for the first 6 hours.

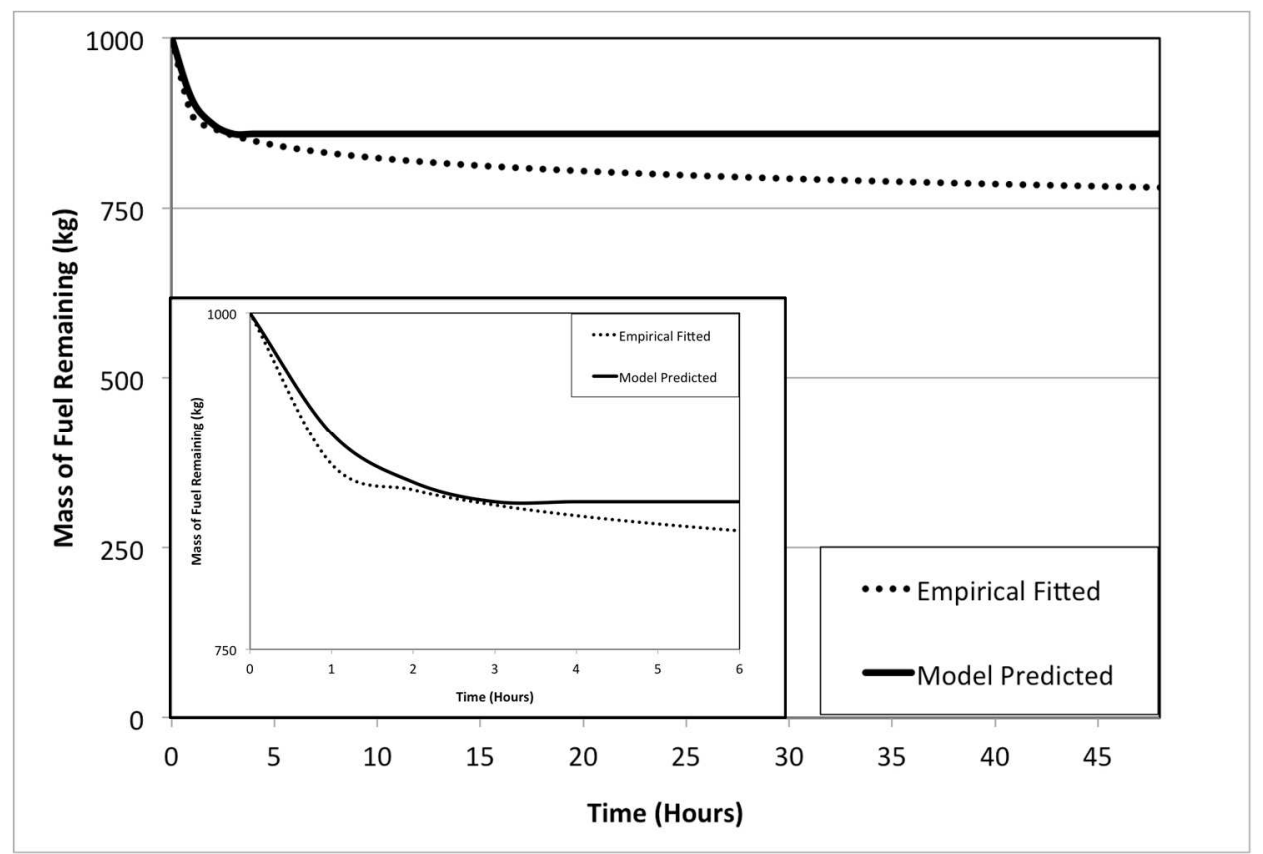


Figure 13: Comparison of laboratory predicted evaporation curve and model predicted evaporation during the first 48 hours for Jet Fuel. Inset picture displays results for the first 6 hours.

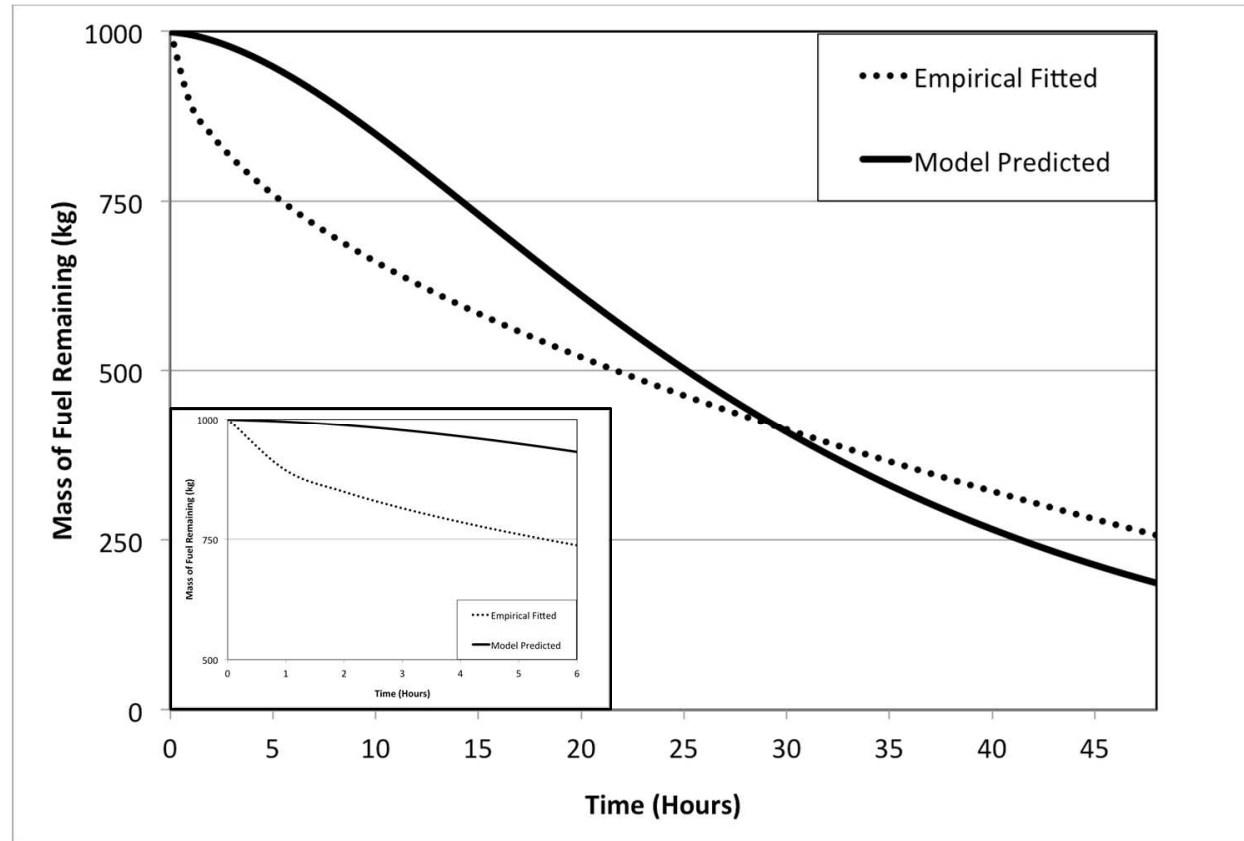




\section{CHAPTER 5}

\section{CONCLUSIONS}

As an operational response model, the current oil spill modeling tools, with simplified compositions and generic constituent class percentages for SARA contents, appear to do a reasonable job at forecasting the fate and transport of crude oils. Reasonable is not clearly defined in this industry as there are no industry-accepted metrics for accuracy of oil spill trajectory forecasts (Fingas 2014). Ideally, analytical results would be available to validate model predictions. During emergency response operations this is rarely the main focus of effort and available data is typically incomplete at best. Uncertainties in the underlying hydrographic and meteorological inputs manifest themselves in inaccurate slick size and overall trajectory. Improper weathering algorithms would amplify these errors.

The evaporation model developed and presented in this work does a reasonable job at estimating the evaporation of fuels and crude oils when spilled and capturing the onset of and method of emulsification, the two main goals of this work. The model is able to capture the general trend of laboratory observations fairly well across a range of fuel densities, and does a reasonable job at capturing the transition from nonemulsified to emulsified oil. The simplified crude oil composition seems, based on the limited comparison to observations presented within this work, to be a useful representation of typical crude oils. This is significant considering that the complexity of crude oil composition was reduced to a list of roughly 300 constituents, and suggests that the compositional distribution from a very limited set of oils can be 
extrapolated to a larger group of oils while still maintaining applicability. The massweighted density calculation replicates empirical data well. The use of a simple film model characterizes the evaporation of materials at the earliest stages of weathering within an acceptable margin of error, providing a conservative estimate of the rate weathering of materials and therefore erring on the side of caution. The noted exception to this was the weathering of Arabian Light crude oil, which did not reach the conditions for a stable emulsion in the model and therefore weathering proceeded at a faster rate than observed.

There are several key areas where adjustments and improvements to the model construct and execution could be made to improve the overall functionality of the model for operational response. The viscosity estimation method is still sub-optimal relative to the reported laboratory results. This is an issue because the calculation of the stability factor used to determine the emulsification state requires a reasonable estimate of viscosity. The friction viscosity method employed represents the current state of the art for calculating crude oil viscosity (Quiñones-Cisneros et al. 2015), however errors or omissions in the individual constituent viscosity calculations causes in errors in the composite calculations. Although model run temperatures were kept to $25^{\circ} \mathrm{C}$ when comparing model predictions to empirical data to avoid any issues that may have arisen from using prescribed constant constituent viscosity values where no fitting data were available, there are several sources of error that may have contributed to the overall viscosity. When calculating the individual constituent contribution to overall viscosity, compound-specific critical parameters are needed. When these data are missing, as is the case for asphaltene, resin, and several of the higher molecular 
weight saturate and aromatic constituents, they were derived from available data. This derived data may contribute to the overall viscosity error, with a simpler formulation providing a more defensible composite viscosity result.

If the availability of critical parameters was used as a criterion for inclusion within the oil formulation, asphaltene and resin contributions to viscosity would be excluded. These contributions are critical to the overall crude oil composition. As characterization of asphaltenic and resinous materials advances through molecular simulation and analytical improvements, current research trends suggest that these broad categories can be divided up, themselves, into more discrete categories based on molecular weight, solubility, and polarity (Li \& Greenfield 2014). Generating subclasses for asphaltenes and resins and including their behavior in the model creates a potential to better tune model results to empirical data, when available. This approach was not attempted in the current work. The anticipated variability between crude oils and within a single reservoir would result in a less generic approach than needed for an operational response crude oil model.

The current model construct allows for addition of new constituents if and when additional molecular information becomes available and/or is required, whether for resolving sub-classes of asphaltenes and resins or adding defined constituents of concern to the saturate and aromatic classes, The data can be added simply as a named constituent within the oil constituent list with an assigned overall mass percentage in the oil and added to the overall chemical database with minimal effort. When viscosity needs to be better matched to known data in order to best replicate environmental behavior, the current methodology to handle that would be to modify 
the asphaltene and/or resin viscosity contribution to the overall oil until a reasonable match to empirical physical properties was achieved by the prescribe oil composition. It may also be useful to implement a hybrid method for determining viscosity by implementing the Beal method for low viscosity fuels and friction theory approach for higher viscosity fuels. This requires knowledge of the fuel viscosity prior to modeling, something that may or may not be available before operation response timelines have been exceeded. Lastly, the limits used to determine the oil emulsion stability class could be tuned to accommodate errors in the viscosity while calculating emulsion state.

The slick spreading algorithm, derived from fundamental principles and first published by Fay in the 1970's, has been documented (Lehr 2001) to be inaccurate for certain conditions. There is little consensus, however, on the best approach to slick spreading. In the current construct, the slick spreading algorithm seems to do a reasonable job when weathering is progressing most quickly, as there were no significant discrepancies within the first 5-10 hours of weathering for the cases highlighted. This does not indicate that spreading approach is valid, but rather, that, with its known errors, it does a reasonable job.

The model stops evaporation once a stable emulsion is reached, however there are still significant viscosity changes that are observed within stable and meso-stable emulsified oils. The viscosity changes currently implemented in the model are derived from observations in (Fingas 2011) however this does not seem to adequately capture the higher viscosity values for emulsified oils as observed in the model-to-data comparisons for the four highlighted oils. A large part of the discrepancy is believed 
to be the result of the non-Newtonian behavior of emulsified oils, likely resulting in an observed viscosity that has a more complex relationship to the shear rate or shear rate history. The friction viscosity approach was initially thought to be better suited to incorporating these variations. Changes to the emulsified oil viscosity algorithms would be very straightforward to implement within the modeling framework if available.

The evaporation rate and viscosity calculations include temperature dependent impacts on property calculations, however the temperature dependence of density is not included. Not including temperature dependence would result in under-predicting the bulk density at lower temperatures; it may impact the ability to predict the emulsion state, and necessitate further adjustment to the stability ranges assigned to each of the emulsion states.

From a response perspective, a reasonable model forecast should provide information that allows for development and implementation of an effective response effort that mitigates the impact of spilled oil. For shoreline spills, this is often not possible due to the disparity between the fine scale of coastal transport processes and the coarse scale of the underlying hydrographic forcing information. Interaction with the shoreline alters the trajectory of spilled oil, and stranded oil exhibits tidally influenced shoreline storage and re-suspension. For offshore spills, it is far more likely that an oil spill forecast would provide a forecast with a smaller error in the direction of oil transport as well as the size of the oil slick generated from a spill. If an operational forecast has a $20 \%$ margin of error, it is typically considered reasonable. 
A skilled forecaster typically qualifies this margin of error, and thus a quantitative metric is still not available.

Model processing times suggest that the complexity of the crude oil composition meets operational requirements to run a 3 day simulation and forecast within 10 minutes. This varies as a function of the number of model parcels used in the Lagrangian modeling framework employed within the system, but a 250 particles as a benchmark is currently being implemented for operational use. The addition of entrainment algorithms, dissolution, and more specific characterization of water infiltration into the crude oil matrix as a function of emulsification state would be expected to enhance the analytical modeling abilities, but add little to the operational application of the model currently.

Finally, to best capture real world dynamics, the implementation of shoreline interactions, including oil grounding and re-suspension from the shoreline, interaction with varying shoreline type as well as inclusion of how shoreline materials dictate overall oil stranding merits additional consideration to better represent oil fate and transport in near-shore environments. 
APPENDICES 
Appendix A.

Oil Composition for Saturate and Aromatic Classes as Mass Percentages of Total Aromatics and Saturates, Respectively.

\section{Saturates}

Butane: $4.4195 \times 10^{-4}$

Pentane: $2.9919 \times 10^{-4}$,

Hexane: $4.1886 \times 10^{-4}$,

Heptane: $2.9919 \times 10^{-4}$,

Octane: $5.9837 \times 10^{-4}$,

Nonane: $1.43 \times 10^{-2}$,

Decane: $1.3 \times 10^{-2}$,

Undecane: $3.68 \times 10^{-2}$,

Dodecane: $2.9482 \times 10^{-2}$,

Tridecane: $4.5399 \times 10^{-2}$,

2,6,10-Trimethyldodecane: $1.6155 \times 10^{-2}$,

Tetradecane: $4.0108 \times 10^{-2}$,

2,6,10-Trimethyltridecane: $1.9400 \times 10^{-2}$,

Pentadecane: $4.6268 \times 10^{-2}$,

Hexadecane: $4.0712 \times 10^{-2}$,

Nor-pristane: $1.6670 \times 10^{-2}$,

Heptadecane: $2.7627 \times 10^{-2}$,

Pristane: $2.1971 \times 10^{-2}$,

Octadecane: $2.4275 \times 10^{-2}$,

Phytane: $1.6532 \times 10^{-2}$,

Nonadecane: $3.3828 \times 10^{-2}$,

Eicosane: $3.1988 \times 10^{-2}$,

Heneicosane: $3.1879 \times 10^{-2}$,

Docosane: $2.5793 \times 10^{-2}$,

Tricosane: $1.8736 \times 10^{-2}$,

Tetracosane: $1.7980 \times 10^{-2}$, Pentacosane: $1.8356 \times 10^{-2}$, Hexacosane: $1.6722 \times 10^{-2}$, Heptacosane: $1.5797 \times 10^{-2}$, Octacosane: $2.5148 \times 10^{-2}$, Nonacosane: $1.5080 \times 10^{-2}$, Triacontane: $1.3273 \times 10^{-2}$, Hentriacontane: $1.2475 \times 10^{-2}$, Dotriacontane: $2.7127 \times 10^{-2}$, Tritriacontane: $1.4088 \times 10^{-2}$, 
Tetratriacontane: $1.3928 \times 10^{-2}$, Pentatriacontane: $1.3291 \times 10^{-2}$, Hexatriacontane: $1.2914 \times 10^{-2}$, Heptatriacontane: $1.3767 \times 10^{-2}$, Octatriacontane: $9.5876 \times 10^{-3}$, Nonatriacontane: $9.6136 \times 10^{-3}$, Tetracontane: $9.0360 \times 10^{-3}$, Isobutane: $9.5549 \times 10^{-4}$, Isopentane: $1.3248 \times 10^{-3}$, Isohexane: $1.2090 \times 10^{-3}$, Neopentane: $2.6927 \times 10^{-4}$, Neohexane: $6.7313 \times 10^{-4}$, Neoheptane: $4.2813 \times 10^{-4}$, 2,3-Dimethylbutane: $3.9941 \times 10^{-4}$, Triptan: $1.6156 \times 10^{-4}$, 3-Methylpentane: $2.1115 \times 10^{-3}$, 2,3-Dimethylpentane: $2.7734 \times 10^{-3}$, 2,4-Dimethylpentane: $1.3921 \times 10^{-3}$, 3,3-Dimethylpentane: $3.5005 \times 10^{-4}$, 2,2,3-Trimethylpentane: $1.1040 \times 10^{-4}$, 2,3,3-Trimethylpentane: $1.3517 \times 10^{-4}$, 2,3,4-Trimethylpentane: $3.0696 \times 10^{-4}$, 2-methyl-3-ethylpentane: $3.3333 \times 10^{-4}$, 2-Methylhexane: $4.8467 \times 10^{-3}$, 3-Methylhexane: $4.3350 \times 10^{-3}$, 2,2-Dimethylhexane: $1.7893 \times 10^{-4}$, 2,3-Dimethylhexane: $1.7893 \times 10^{-4}$, 2,4-Dimethylhexane: $2.7061 \times 10^{-4}$, 2,5-Dimethylhexane: $2.1003 \times 10^{-4}$, 3,3-Dimethylhexane: $2.1003 \times 10^{-4}$, 2,3,4-Trimethylhexane: $2.1003 \times 10^{-4}$, 2,2,5-Trimethylhexane: $2.1003 \times 10^{-4}$, 2,3,5-Trimethylhexane: $2.1003 \times 10^{-4}$, 3-Ethylhexane: $4.7862 \times 10^{-4}$, 2-Methylheptane: $1.3571 \times 10^{-3}$, 3-Methylheptane: $7.5529 \times 10^{-3}$, 4-Methylheptane: $4.4429 \times 10^{-3}$, 2,3-Dimethylheptane: $4.0390 \times 10^{-4}$, 3,4-Dimethylheptane: $4.0390 \times 10^{-4}$, 3,5-Dimethylheptane: $4.0390 \times 10^{-4}$, 4-Ethylheptane: $9.6935 \times 10^{-3}$, 
2-Methyloctane: $1.0299 \times 10^{-2}$,

3-Methyloctane: $9.6531 \times 10^{-3}$,

4-Methyloctane: $5.4526 \times 10^{-3}$,

Cyclopentane: $4.2005 \times 10^{-3}$,

Methylcyclopentane: $5.3518 \times 10^{-3}$,

1,1-Dimethylcyclopentane: $2.7061 \times 10^{-3}$, cis-1,3-Dimethylcyclopentane: $5.6546 \times 10^{-3}$, trans-1,2-Dimethylcyclopentane: $9.2896 \times 10^{-3}$, trans-1,3-Dimethylcyclopentane: $6.0988 \times 10^{-3}$, 1,1,2-Trimethylcyclopentane: $2.8677 \times 10^{-3}$, 1,1,3-Trimethylcyclopentane: $2.8677 \times 10^{-3}$, 1,2,3-Trimethylcyclopentane: $2.8677 \times 10^{-3}$, 1,2,4-Trimethylcyclopentane: $2.8677 \times 10^{-3}$, Ethylcyclopentane: $3.1100 \times 10^{-3}$, Isopropylcyclopentane: $1.7771 \times 10^{-3}$,

Cyclohexane: $1.3813 \times 10^{-2}$, Methylcyclohexane: $2.2465 \times 10^{-2}$, 1,1-Dimethylcyclohexane: $6.0584 \times 10^{-3}$, Heptene: $9.0473 \times 10^{-3}$, Methyldecalin: $2.9081 \times 10^{-3}$, 2-Methyldecalin: $4.3621 \times 10^{-3}$, Ethyldecalin: $1.8216 \times 10^{-3}$, 2,6-Dimethyldecalin: $1.8216 \times 10^{-3}$, 1,1,2-Trimethyldecalin: $1.7004 \times 10^{-3}$, Butyldecalin: $6.2200 \times 10^{-4}$, Isobutyldecalin: $6.2200 \times 10^{-4}$

\section{Aromatics}

Benzene: $4.0346 \times 10^{-2}$,

Toluene: $1.0929 \times 10^{-1}$, Ethylbenzene: $2.3459 \times 10^{-2}$, o-Xylene: $4.4320 \times 10^{-2}$, m-Xylene: $6.0015 \times 10^{-2}$, p-Xylene: $6.0015 \times 10^{-2}$, Cumene: $6.6898 \times 10^{-3}$, Propylbenzene: $1.0763 \times 10^{-2}$, 1-ethyl,3-methylbenzene: $2.8425 \times 10^{-2}$, p-Ethyltoluene: $1.1955 \times 10^{-2}$, 1,3,5-Trimethylbenzene: $3.7366 \times 10^{-2}$, 1-ethyl,2-methylbenzene: $1.3088 \times 10^{-2}$, Pseudocumene: $5.36575 \times 10^{-2}$, 
1,2-Diethylbenzene: $4.288359 \times 10^{-3}$, o-Propyltoluene: $6.9537 \times 10^{-3}$, m-Propyltoluene: $1.3192 \times 10^{-2}$, p-Propyltoluene: $5.3842 \times 10^{-3}$, Butylbenzene: $5.1060 \times 10^{-3}$, sec-butylBenzene: $5.1457 \times 10^{-3}$, o-Cymene: $9.2782 \times 10^{-4}$, m-Cymene: $6.4967 \times 10^{-3}$, p-Cymene: $3.6159 \times 10^{-3}$, p-Xylene,2-ethyl-: $6.4769 \times 10^{-3}$, o-Xylene,4-ethyl-: $9.5762 \times 10^{-3}$, m-Xylene,2-ethyl-: $2.0265 \times 10^{-3}$, 1-ethyl-2,4-dimethylbenzene: $6.8544 \times 10^{-3}$, 1-ethyl-3,5-dimethylbenzene: $8.7021 \times 10^{-3}$, 1-ethyl-2,3-dimethylbenzene: $3.0795 \times 10^{-3}$, 1,2,4,5-Tetramethylbenzene: $1.0073 \times 10^{-2}$, Pentylbenzene: $9.9736 \times 10^{-4}$, Naphthalene: $1.5914 \times 10^{-2}$, 1-Methylnaphthalene: $2.1457 \times 10^{-2}$, 2-Methylnaphthalene: $3.4172 \times 10^{-2}$, 1,2-Dimethylnaphthalene: $9.9339 \times 10^{-3}$, 1,6-Dimethylnaphthalene: $9.9339 \times 10^{-3}$, 2-Ethylnaphthalene: $9.9339 \times 10^{-3}$, 2,6-Dimethylnaphthalene: $9.9339 \times 10^{-3}$, 2,3,6-Trimethylnaphthalene: $2.9404 \times 10^{-2}$, 1-Butylnaphthalene: $1.3292 \times 10^{-2}$, Fluorene: $3.0398 \times 10^{-3}$, 1-Methylfluorene: $6.2186 \times 10^{-3}$, 9-Ethylfluorene: $8.1259 \times 10^{-3}$, Dibenzothiophene: $1.0371 \times 10^{-3}$, 1-Methyldibenzothiophene: $3.0199 \times 10^{-3}$, 2-Methylbenzothiophene: $1.2914 \times 10^{-3}$, 4-Methyldibenzothiophene: $1.2914 \times 10^{-3}$, 3-Methyldibenzo[b,d]thiophene: $1.2914 \times 10^{-3}$, 3-Ethyldibenzothiophene: $1.8378 \times 10^{-3}$, 4-Ethyldibenzothiophene: $1.8378 \times 10^{-3}$, 2,7-Dimethyldibenzothiophene: $1.8378 \times 10^{-3}$, 4,6-Dimethyldibenzothiophene: $1.8378 \times 10^{-3}$, 1,2,3-Trimethyldibenzothiophene: $1.9868 \times 10^{-3}$, 2,4,8-Trimethyldibenzothiophene: $1.9868 \times 10^{-3}$, 4-Ethyl-6-methyldibenzothiophene: $1.9868 \times 10^{-3}$, 
3,4,6,7-tetramethyldibenzothiophene: $1.1921 \times 10^{-3}$, 4,6-Diethyldibenzothiophene: $1.1921 \times 10^{-3}$, 6-Ethyl,2,4-dimethyldibenzothiophene: $1.1921 \times 10^{-3}$, Phenanthrene: $6.1789 \times 10^{-3}$, 1-Methylphenanthrene: $3.0199 \times 10^{-3}$, 2-Methylphenanthrene: $3.0199 \times 10^{-3}$, 3-Methylphenanthrene: $3.0199 \times 10^{-3}$, 9-Methylphenanthrene: $3.0199 \times 10^{-3}$, 2-Methylanthracene: $3.0199 \times 10^{-3}$, 3,6-Dimethylphenanthrene: $4.0729 \times 10^{-3}$, 3-Ethylphenanthrene: $4.0729 \times 10^{-3}$, 2-Ethylanthracene: $4.0729 \times 10^{-3}$, 1,9-Dimethylanthracene: $4.0729 \times 10^{-3}$, 1,2,8-Trimethylphenanthrene: $2.3047 \times 10^{-3}$, 9-Ethyl-10-methylphenanthrene: $2.3047 \times 10^{-3}$, 1-Propylphenanthrene: $2.3047 \times 10^{-3}$, 2,7,9-trimethylanthracene: $2.3047 \times 10^{-3}$, 9-Propylanthracene: $2.3047 \times 10^{-3}$, 2,4,5,7-Tetramethylphenanthrene: $9.2716 \times 10^{-4}$, 1,3,5,7-Tetramethylanthracene: $9.2716 \times 10^{-4}$, 9,10-Diethylphenanthrene: $9.2716 \times 10^{-4}$, Retene: $9.2716 \times 10^{-4}$, 9-Butylphenanthrene: $9.2716 \times 10^{-4}$, 9-Butylanthracene: $9.2716 \times 10^{-4}$, Fluoranthene: $9.1392 \times 10^{-2}$, Pyrene: $3.5961 \times 10^{-4}$, 1-Methylpyrene: $2.3841 \times 10^{-3}$, 2,7-Dimethylpyrene: $1.2583 \times 10^{-3}$, 1-Ethylpyrene: $1.2583 \times 10^{-3}$, 4-Ethylpyrene: $1.2583 \times 10^{-3}$, 1,2,3-Trimethylpyrene: $1.0431 \times 10^{-3}$, 4-Ethyl,5-methylpyrene: $1.0431 \times 10^{-3}$, Propylpyrene: $1.0431 \times 10^{-3}$, 4-Propylpyrene: $1.0431 \times 10^{-3}$, 4,5-Diethylpyrene: $7.4504 \times 10^{-4}$, 4-Ethyl,5,10-dimethylpyrene: $7.4504 \times 10^{-4}$, 1-Butylpyrene: $7.4504 \times 10^{-4}$, 1,2,3,4-Tetramethylfluoranthene: $7.4504 \times 10^{-4}$, Benzo[a]anthracene: $2.9802 \times 10^{-4}$, Chrysene: $1.0808 \times 10^{-3}$, 6-Methylchrysene: $2.5431 \times 10^{-3}$, 
5,6-Dimethylchrysene: $3.0000 \times 10^{-3}$, 1,3,6-Trimethylchrysene: $5.9603 \times 10^{-4}$, 1-Ethyl,2-methylchrysene: $5.9603 \times 10^{-4}$, 6-Ethyl,5-methylchrysene: $5.9603 \times 10^{-4}$, 2,4,5-Trimethylchrysene: $5.9603 \times 10^{-4}$, 6-Propylchrysene: $5.9603 \times 10^{-4}$, 1,2,7,8-tetramethylchrysene: $7.2848 \times 10^{-3}$, 6,12-Diethylchrysene: $7.2848 \times 10^{-3}$, 6-Butylchrysene: $7.2848 \times 10^{-3}$, Benzo[b]fluoranthene: $1.0967 \times 10^{-4}$, Benzo[a]fluoranthene: $2.0066 \times 10^{-5}$, Benzo[e]pyrene: $2.4040 \times 10^{-4}$, Benzo[a]pyrene: $5.7418 \times 10^{-5}$, Perylene: $2.2848 \times 10^{-5}$, o-Phenylenepyrene: $1.7643 \times 10^{-5}$, Dibenzo[a,h]anthracene: $4.0928 \times 10^{-5}$, Benzo[g,h,i]perylene: $4.3908 \times 10^{-5}$, Biphenyl: $3.6557 \times 10^{-3}$, Dibenzofuran: $5.3643 \times 10^{-4}$, Acenaphthylene: $1.5894 \times 10^{-4}$, Acenaphthene: $4.5696 \times 10^{-4}$, Indane: $1.3331 \times 10^{-3}$, Benzo[b]fluorene: $2.3444 \times 10^{-4}$, Thiophene: $3.6159 \times 10^{-4}$, 2-Methylthiophene: $1.0768 \times 10^{-3}$, 3-Methylthiophene: $1.6033 \times 10^{-3}$, 2-Ethylthiophene: $1.9113 \times 10^{-3}$, Benzo[b]thiophene: $1.3907 \times 10^{-4}$, 3-Methylbenzo[b]thiophene: $1.9868 \times 10^{-4}$, 4-Methylbenzo[b]thiophene: $1.9868 \times 10^{-4}$, 5-Methylbenzo[b]thiophene: $1.9868 \times 10^{-4}$, 5-Ethylbenzo[b]thiophene: $1.8543 \times 10^{-4}$, 3,5-Dimethylbenzo[b]thiophene: $1.8543 \times 10^{-4}$, 2-Ethylbenzothiophene: $1.8543 \times 10^{-4}$, 2-Propylbenzothiophene: $4.4371 \times 10^{-4}$, 2,5,7-Trimethylbenzo(b)thiophene: $4.4371 \times 10^{-4}$ 


\section{BIBLIOGRAPHY}

Almeda, R. et al., 2013. Effects of Crude Oil Exposure on Bioaccumulation of Polycyclic Aromatic Hydrocarbons and Survival of Adult and Larval Stages of Gelatinous Zooplankton. PLoS ONE, 8(10).

Baylaucq, A. et al., 2006. Dynamic Viscosity Modeling of Methane + n- Decane and Methane + Toluene Mixtures : Comparative Study of Some Representative Models. , 6466(October 2015).

Canada, E., Environment Canada Oil Properties Database. Environment. Available at: http://www.etc-cte.ec.gc.ca/databases/oilproperties/ [Accessed April 1, 2016].

Chang, S.E. et al., 2014. Consequences of oil spills: A review and framework for informing planning. Ecology and Society, 19(2).

Deacon, E.L., 1977. Gas transfer to and across an air/water interface. Tellus, 29(4), pp.363-374.

Dietrich, D.E. et al., 2014. Oil Spill Risk Management: Modeling Gulf of Mexico Circulation and Oil Dispersal, Hoboken, NJ: Scrivener Publishing LLC.

Fay, J.A., 1969. The spread of oil slicks on calm sea. In Proceedings of a symposium on the scientific and engineering aspects of oil pollution of the sea. pp. 53-63.

Fingas, M., 2014. Handbook of Oil Spill Science and Technology. In M. Fingas, ed. Hoboken, NJ: John Wiley \& Sons, Inc, p. 728.

Fingas, M., 2011. Models for Water-in-Oil Emulsion Formation, Available at: http://dx.doi.org/10.1016/B978-1-85617-943-0.10010-3.

Fingas, M.F., 1999. the Evaporation of Oil Spills : Development and Implementation of New Prediction Methodology. Intenational Oil Spill Conference, pp.281-287. 
Available at:

http://www.ioscproceedings.org/toc/iosc/1999/1 \nhttp://www.ioscproceedings.or g/doi/pdf/10.7901/2169-3358-1999-1-

281 nhttp://www.ioscproceedings.org/doi/pdf/10.7901/2169-3358-1999-1-i.

Fingas, M.F., 2014. Water-in-oil emulsions: formation and prediction. Journal of Petroleum Science Research, 3(1), p.38. Available at: http://www.jpsr.org//PaperInfo.aspx?ID=10236.

Fuller, E., Schettler, P. \& Giddings, J.C., 1966. A new method for prediction of binary gas. Industrial and Engineering Chemistry, 58(5), pp.18-27.

Garrett, R.M. et al., 1998. Photooxidation of crude oils. Environmental Science and Technology, 32(23), pp.3719-3723.

ITOPF, I.T.O.P.F., 2016. ITOPF. Available at: http://www.itopf.com/knowledgeresources/documents-guides/fate-of-oil-spills/weathering/ [Accessed August 26, 2016].

Jones, J.C., 2012. Hydrocarbons - Physical Properties and their Relevance to Utilisation, Available at: http://bookboon.com/en/textbooks/chemistry-chemicalengineering/hydrocarbons.

Lehr, W.J., 2001. Review of modeling procedures for oil spill weathering behavior. Advances in Ecological Sciences, 9, pp.51-90.

Leirvik, F. \& Myrhaug, J.L., 2009. Sintef report: Weathering properties of the Alvheim crude oils Kneler, Boa, Kameleon, and the Alvheim blend,

Li, D.D. \& Greenfield, M.L., 2014. Chemical compositions of improved model asphalt systems for molecular simulations. Fuel, 115, pp.347-356. 
Liu, Y. \& Kujawinski, E.B., 2015. Chemical composition and potential environmental impacts of water-soluble polar crude oil components inferred from esi FT-ICR MS. PLoS ONE, 10(9).

Manning, F.S. \& Thompson, R.E., 1995. OILFIELD PROCESSING Volume Two: Crude Oil Second., Tulsa: PennWell Publishing Company.

Mobil Research and Engineering, 1997. Petroleum Manufacturing Orientation Course, Paulsboro, NJ.

Moreno, R. et al., 2013. Ten years after the prestige oil spill: seabird trophic ecology as indicator of long-term effects on the coastal marine ecosystem. PloS one, 8(10), p.e77360. Available at:

http://www.pubmedcentral.nih.gov/articlerender.fcgi?artid=3793948\&tool=pmce ntrez\&rendertype $=$ abstract.

Nayar, K.G. et al., 2016. Thermophysical properties of seawater: A review and new correlations that include pressure dependence. Desalination, 390, pp.1-24.

NOAA, 2012. Open Water Oil Identification Job Aid for Aerial Observation. Available at: http://response.restoration.noaa.gov/sites/default/files/OWJA_2012.pdf.

NOAA/ORA/ESRL PSD, NCEP Reanalysis Derived data provided by the NOAA/OAR/ESRL PSD. , p.http://www.esrl.noaa.gov/psd/data/gridded/data.nce. Available at: http://www.esrl.noaa.gov/psd/ [Accessed February 4, 2016].

Quiñones-cisneros, S.E. et al., 2008. Friction Theory Modeling of the Non-Newtonian Viscosity of Crude Oils †., 110(25), pp.799-804.

Quiñones-cisneros, S.E. et al., 2015. PVT Characterization and Viscosity Modeling 
and Prediction of Crude Oils. , 6466(October).

Quiñones-Cisneros, S.E. et al., 2004. Viscosity modeling and prediction of reservoir fluids: From natural gas to heavy oils. International Journal of Thermophysics, 25(5), pp.1353-1366.

Quiñones-Cisneros, S.E. \& Deiters, U.K., 2006. Generalization of the friction theory for viscosity modeling. Journal of Physical Chemistry B, 110, pp.12820-12834.

Quiñones-Cisneros, S.E., Zéberg-Mikkelsen, C.K. \& Stenby, E.H., 2003. Friction theory prediction of crude oil viscosity at reservoir conditions based on dead oil properties. Fluid Phase Equilibria, 212, pp.233-243.

Quiñones-Cisneros, S.E., Zéberg-Mikkelsen, C.K. \& Stenby, E.H., 2001a. One parameter friction theory models for viscosity. Fluid Phase Equilibria, 178, pp.1-16.

Quiñones-Cisneros, S.E., Zéberg-Mikkelsen, C.K. \& Stenby, E.H., 2001b. The friction theory for viscosity modeling: Extension to crude oil systems. Chemical Engineering Science, 56, pp.7007-7015.

Reddy, C.M. et al., 2012. Composition and fate of gas and oil released to the water column during the Deepwater Horizon oil spill. Proceedings of the National Academy of Sciences , 109 (50), pp.20229-20234. Available at: http://www.pnas.org/content/109/50/20229.abstract.

Ryerson, T.B. et al., 2012. Chemical data quantify Deepwater Horizon hydrocarbon flow rate and environmental distribution. Proceedings of the National Academy of Sciences, 109(50), pp.20246-20253.

Sanchez-Minero, F. et al., 2013. Predicting SARA composition of crude oil by means 
of NMR. Fuel, 110, pp.318-321.

Sharqawy, M.H., Lienhard V, J.H. \& Zubair, S.M., 2011. Erratum to Thermophysical properties of seawater: A review of existing correlations and data. Desalination and Water Treatment, 29(1-3), pp.355-355.

Sørheim, K.R., Altin, D. \& Leirvik, F., 2011. Gjøa crude oil - Weathering propertires related to oil spill response, and chemical and toxicological characterization of $W A F$, Trondheim.

Thingstad, T. \& Pengerud, B., 1983. The formation of "chocolate mousse" from Statfjord crude oil and seawater. Marine Pollution Bulletin, 14(6), pp.214-216. 